\title{
PREVENIR LOS DISTURBIOS Y LAS ENFERMEDADES: ESTRATEGIAS Y POLÍTICAS ALEMANAS DURANTE LA HAMBRUNA HOLANDESA DE 1944-1945
}

\author{
Preventing Unrest and Disease: German Strategies and Policies during the Dutch \\ Famine of 1944-1945
}

\author{
Ingrid de Zwarte \\ Wageningen University \\ i.de.zwarte@niod.knaw.nl
}

Recibido: 05-05-2020 - Aceptado: 29-07-2020

Cómo citar este artículo/Citación:

Ingrid De Zwarte, "Prevenir los disturbios y las enfermedades: estrategias y políticas alemanas durante la hambruna holandesa de 1944-1945", Hispania Nova, 19 (2021): 733 a 775.

DOI: https://doi.org/10.20318/hn.2021.5896
Copyright: (C) HISPANIA NOVA es una revista debidamente registrada, con ISSN 1138-7319 y Depósito Legal M 9472-1998. Los textos publicados están -si no se indica lo contrario- bajo una licencia Reconocimiento-Sin obras derivadas 3.0 España de Creative Commons. Puede copiarlos, distribuirlos y comunicarlos públicamente siempre que cite su autor y la revista y la institución que los publica y no haga con ellos obras derivadas. La licencia completa se puede consultar en: http://creativecommons.org/licenses/by-nd/3.0/es/deed.es
Resumen: La hambruna holandesa de 1944-1945, conocida popularmente como el "Invierno del Hambre", ha sido comúnmente vista como el resultado de las políticas alemanas en relación al hambre, desarrolladas por la Alemania nazi también en otras partes de Europa durante la Segunda Guerra Mundial. Este artículo cuestiona estas suposiciones sobre la política de hambre de las autoridades de ocupación alemana en los Países Bajos, centrándose en la complejidad del gobierno alemán durante las fases finales de la guerra. A partir de fuentes de origen holandés, alemán y aliado, este artículo argumenta que la hambruna fue causada y exacerbada por una compleja culminación de varios problemas de transporte y distribución. También demuestra cómo y por qué a partir de finales de 1944 las autoridades civiles alemanas encontraron razones para colaborar con los funcionarios holandeses encargados de la alimentación para prevenir el empeoramiento de la situación y permitir el alivio de los holandeses hambrientos. Se propone, por tanto, un cambio de un marco explicativo monocausal y altamente politizado a uno que revela las múltiples dimensiones de la hambruna.

Palabras clave: Segunda Guerra Mundial, Países Bajos, Ocupación alemana, Hambruna, "Invierno del hambre". 
Abstract: The Dutch famine of 1944-1945, popularly known as the 'Hunger Winter', has commonly been viewed as the result of German hunger politics, which Nazi Germany also pursued elsewhere in Europe during WWII. This article challenges these assumptions about the famine politics of the German occupation authorities in the Netherlands by focusing on the complexity of German governance during the final phases of the war. Based on Dutch, German and Allied source materials, this article argues that the famine was caused and exacerbated by a complex culmination of several transportation and distribution problems.
It also demonstrates how and why from late 1944 onward the German civil authorities found reasons to collaborate with Dutch food officials to prevent worse from happening and allow relief for the starving Dutch. In doing so, a shift is proposed from a mono-causal, highlypoliticized explanatory framework to one that reveals the multiple dimensions of the famine.

Keywords: Second World War, the Netherlands, German Occupation, Famine, "Hunger Winter"

\section{INTRODUCCIÓN*}

Durante la Segunda Guerra Mundial, los alimentos se convirtieron en un elemento clave en las políticas de ocupación de la Alemania nazi. A lo largo de la guerra, el sector agrícola alemán se esforzó por producir suficiente comida para dar raciones apropiadas a los civiles alemanes y la Wehrmacht. A esto se añadía la necesidad de alimentar a un número creciente de trabajadores forzados para continuar la productividad a favor de la economía de guerra alemana. En esa búsqueda de seguridad alimentaria del Reich, los países considerados inferiores fueron espoliados de recursos, sobre todo Ucrania y Polonia. ${ }^{1}$ Además, la comida y el hambre, en general, se convirtieron en dos de las principales armas de guerra y represión de la Alemania nazi.

Al igual que los cientos de miles de judíos que murieron de hambre en guetos y en campos de concentración, se estima que tres millones de prisioneros de guerra soviéticos fueron matados de hambre a propósito como parte de la política de hambruna nazi. $^{2}$ A pesar de que los alemanes se centraron en Europa oriental como fuente de

\footnotetext{
* Esta contribución se basa en mi tesis doctoral y en el libro The Hunger Winter: Fighting Famine in the Occupied Netherlands, 1944-1945 (Cambridge, 2020). Prometheus ha publicado una versión holandesa popular de mi thesis: De Hongerwinter (Ámsterdam, 2019).

${ }^{1}$ Adam Tooze, The Wages of Destruction: The Making and Breaking of the Nazi Economy (Londres: Allen Lane, 2006), pp. 520, 538-539; Gesine Gerhard, Nazi Hunger Politics: A History of Food in the Third Reich (Lanham, 2015); Lizzie Collingham, The Taste of War: World War Two and the Battle for Food (Londres, 2011), pp. 155-164; Karel C. Berkhoff, Harvest of Despair: Life and Death in Ukraine under Nazi Rule (Cambridge Mass., 2004); Martin Winstone, The Dark Heart of Hitler's Europe: Nazi Rule in Poland under the General Government (Nueva York, 2015).

${ }^{2}$ Para una excelente panorámica sobre este asunto, ver Gerhard Hirschfeld, 'Chronology of Destruction', in Policies of Genocide: Jews and Soviet Prisoners of War in Nazi Germany, ed. Idem (Boston, 1986), pp. 145-56. Véase también: Christian Gerlach, Krieg, Ernährung, Völkermord: Deutsche Vernichtuinspolitiek im Zweiten Weltkrieg (Zúrich, 2001), pp. 154-156; Gerhard, "Food and Genocide: Nazi Agrarian Politics
} 
saqueos, se ha demostrado que Europa occidental contribuyó más a su suministro de alimentos durante la guerra que toda la Unión Soviética. Durante el proceso de creación de un imperio autosuficiente, el hambre se exportó a países como Noruega, Bélgica y Francia mediante la explotación y la imposición de raciones pequeñas. De hecho, gente de todas partes de Europa sufrieron de escasez alimentaria, en particular, en la Grecia ocupada en 1941-44 que añadió mayor sufrimiento al experimentado por la población de Europa Oriental. ${ }^{3}$ Como afirmó Hermann Göring en una reunión con los líderes de toda la Europa ocupada el 6 de agosto de 1942: "El Fuhrer dijo repetidamente, y yo repito tras él, que si alguien tiene que pasar hambre no van a ser los alemanes, sino otros." ${ }^{4}$

Este artículo estudia las estrategias y políticas alemanas durante la hambruna holandesa de 1944-45, conocida popularmente como el "Invierno del Hambre". La hambruna holandesa representa un caso especialmente interesante para evaluar las políticas alimentarias y la gestión del hambre al ser la única hambruna en toda regla que golpeó la Europa noroccidental. Además, siguen existiendo importantes equivocaciones sobre el papel alemán en esa crisis. Según estudios anteriores, los ocupantes alemanes prohibieron el transporte de todo alimento a las zonas urbanas del oeste de los Países Bajos desde septiembre de 1944 en adelante, creando y manteniendo deliberadamente condiciones de hambruna. ${ }^{5}$ Incluso se ha asumido que los alemanes cortaron el suministro de alimentos al igual que de otros productos básicos como gas, electricidad y agua a los Países Bajos durante los últimos meses de guerra. ${ }^{6}$ Según esos trabajos, la

in the Occupied Territories of the Soviet Union," Contemporary European History 18 (2009): 45-65; Timothy Snyder, Bloodlands: Europe Between Hitler and Stalin (Londres, 2011), pp. 162-182; Alex de Waal, Mass Starvation: The History and Future of Famine (Cambridge, 2018), pp. 101-105.

${ }^{3}$ Polymeris Voglis, "Surviving Hunger: Life in the Cities and the Countryside during the Occupation," en Surviving Hitler and Mussolini: Daily Life in Occupied Europe, eds. Robert Gildea, Olivier Wieviorka y Anette Warring (Oxford, 2006), 16-41; Violetta Hionidou, Famine and Death in Occupied Greece, 19411944 (Cambridge, 2006); Tatjana Tönsmeyer, "Supply Situations: National Socialist Policies of Exploitation and Economies of Shortage in Occupied Societies during World War II," en Coping with Hunger and Shortage under German Occupation in World War II, eds. Tönsmeyer, Peter Haslinger and Agnes Laba (Londres, 2018), pp. 3-23.

${ }^{4}$ Citado en: Collingham, The Taste of War, p. 156.

${ }^{5}$ Por ejemplo: Walter B. Maas, The Netherlands at War: 1940-1945 (Londres, 1970), p. 205; Wallace R. Aykroyd, The Conquest of Famine (Londres, 1974), pp. 98-103; Zena Stein, Mervyn Susser, Gerhard Saenger, Famine and Human Development: The Dutch Hunger Winter of 1944-1945 (Nueva York, 1975), p. 44; Stephen Devereux, Theories of Famine (Nueva York, 1993), p. 160; Voglis, 'Surviving Hunger', p. 22; Mark Mazower, Hitler's Empire: How the Nazis Ruled Europe (Nueva York, 2008), pp. 280-81; Kevin Lowe, Savage Continent: Europe in the Aftermath of World War II (Londres, 2012), pp. 34-37, 160.

${ }^{6}$ Collingham, The Taste of War, p. 176. 
hambruna holandesa fue el resultado de una medida de castigo colectivo por parte de los nazis, única en el contexto de Europa occidental: "Las poblaciones eslavas han sido sujetas a este tratamiento, pero no el europeo occidental." ${ }^{7}$

Este artículo adopta un enfoque diferente en lo que se refiere al papel de Alemania durante la hambruna holandesa, analizando tanto las políticas como la toma de decisiones del ocupante, a la vez que tiene en cuenta la naturaleza heterogénea de la administración alemana en esa época. Al hacerlo, el estudio se basa en los trabajos anteriores de Trienekens, Klemann y Futselaar, entre otros, quienes también tomaron una postura crítica a la responsabilidad que se adjudicó unilateralmente al ocupante alemán por causar la hambruna. ${ }^{8}$ No obstante, este artículo añade una nueva dimensión a nuestra comprensión actual al ser el primero que incluye las perspectivas holandesa, alemana y aliada, así como fuentes primarias posteriores. Esto me permite examinar las políticas y toma de decisiones con mucho más detalle que en estudios anteriores. E1 objetivo principal de este artículo es revelar la complejidad del gobierno alemán durante la última etapa de la guerra, desafiando suposiciones pasadas sobre las políticas de hambruna alemanas en los Países Bajos.

Desde esta perspectiva, el estudio examina una gran variedad de fuentes primarias. Esas fuentes incluyen informes oficiales, minutas, y correspondencia tanto de la administración holandesa como alemana conservadas en los Archivos Nacionales de La Haya y en el Bundesarchiv en Berlin-Lichterfelde. Los informes militares y correspondencia de los aliados conservados en los Archivos Nacionales de Kew, Londres, y en el National Archives and Record Administration en College Park, en Maryland, dan un mayor conocimiento sobre el contexto internacional general en el que se tomaron las decisiones. Además, los diarios de guerra y correspondencia privada proporcionan un mejor entendimiento de las consideraciones personales y las

\footnotetext{
${ }^{7}$ Ian Buruma, Year Zero: A History of 1945 (Nueva York, 2013), p. 54.

${ }^{8}$ Gerard M.T. Trienekens, Tussen ons Volk en de Honger: De Voedselvoorziening 1940-1945 (Utrecht, 1985), p. 383; Trienekens, "The Food Supply in The Netherlands during the Second World War," en Food, Science, Policy and Regulation in the Twentieth Century: International and Comparative Perspectives, eds. David F. Smith y Jim Phillips (Londres, 2000), pp. 117-134; Hein A.M. Klemann, Nederland 1938-1948: Economie en Samenleving in Jaren van Oorlog en Bezetting (Amsterdam, 2002), pp. 465-466; Ralf D. Futselaar, Lard, Lice and Longevity: A Comparative Study on the Standard of Living in Occupied Denmark and the Netherlands, 1940-1945 (Amsterdam, 2008), p. 33.
} 
justificaciones de las decisiones y políticas tanto de oficiales holandeses como alemanes.

A continuación, el artículo se estructura de la siguiente forma: La sección II presenta el contexto histórico del régimen de ocupación alemana en los Países Bajos antes de la hambruna, en los años 1940-44. La sección III examina la actitud alemana en la fase temprana de escasez alimentaria, tras la invasión de los aliados en septiembre de 1944. A continuación, el artículo se centra en las políticas alemanas durante la hambruna relativas al restablecimiento del sistema alimentar (Sección IV) y las medidas de descentralización (Sección V). La sección VI lleva ese análisis al contexto internacional e investiga las negociaciones entre Alemania y los aliados sobre la ayuda alimentaria a los Países Bajos ocupados. Yo argumentaré que la hambruna fue causada y exacerbada por una compleja culminación de varios problemas de transporte y distribución. También demostraré cómo y por qué a partir de finales de 1944 las autoridades civiles alemanas encontraron motivos para colaborar con los funcionarios holandeses encargados de la alimentación para que la ayuda llegase a los holandeses hambrientos. Se propone, por tanto, un cambio de un marco explicativo mono-causal y altamente politizado a uno que revela las múltiples dimensiones de la hambruna.

\section{POLÍTICA ALIMENTARIA ALEMANA ANTES DE LA HAMBRUNA}

Para entender las decisiones que tomó Alemania durante la hambruna, primero hay que fijarse en la política alimentaria del régimen de ocupación antes del otoño de 1944. Poco después de la rendición holandesa a la Alemania nazi en 1940, Adolf Hitler firmó un decreto designando una administración civil alemana para los Países Bajos ocupados. La decisión de instalar una administración civil se debió tanto a consideraciones ideológicas como militares, mientras que en la Bélgica ocupada se instauró una administración militar debido al valor estratégico de su costa. Por el contrario, los Países Bajos fueron considerados menos importantes estratégicamente pero con mucho mayor potencial ideológico para la Alemania nazi. Los líderes nazis consideraron incorporar a los Países Bajos "germanos" en el Tercer Reich y, para ello, era fundamental un periodo de educación y nazificación bajo la supervisión alemana. ${ }^{9}$

\footnotetext{
9 Bob Moore, "The Netherlands, 1940-45," en The Civilian in War: Occupation and the Home Front in World War II, ed. Jeremy Noakes (Exeter, 1992), 129.
} 
El 29 de mayo de 1940, el letrado austríaco y político nazi Arthur Seyss-Inquart fue nombrado Reichskommissar del país. Él actuaría como el mayor administrador civil con el apoyo de su propio gobierno y de la policía e instituciones judiciales alemanas. Esas entidades alemanas operarían en paralelo y al mando de la policía y servicios judiciales holandeses. El General der Flieger Friedrich Christiansen, fue nombrado Wehrmachtbefehlshaber (Comandante de la Wehrmacht) junto con Seyss-Inquart para todos los asuntos relacionados con la guerra y la defensa. También tenía autorización para emitir medidas con rango de ley si fuese necesario para la ejecución de tareas militares o para la "seguridad militar" de los Países Bajos. ${ }^{10}$

Seyss-Inquart recibió el mandato de tratar a los holandeses cuidadosa y adecuadamente, en línea con los objetivos ideológicos y económicos de la Alemania nazi en ese país. Recibió dos instrucciones específicas de Hitler: no dejar que las condiciones de vida en los Países Bajos cayeran por debajo de los niveles en Alemania y fusionar la industria holandesa con la economía bélica alemana. Según Hitler, había que ganarse el corazón de los holandeses hacia el Nacionalsocialismo para que reestructuraran voluntariamente su sociedad según sus líneas ideológicas, lo que muestra la posición relativamente "privilegiada" que los líderes nazis dieron a los supuestos holandeses "arios" comparados con otros pueblos ocupados en Europa. ${ }^{11}$

La administración civil alemana en los Países Bajos ocupados era bastante reducida y su función principal era la supervisión. La gestión diaria del país seguía en manos de funcionarios holandeses, liderados por Secretarios Generales holandeses de antiguos ministerios, a los que se les ordenó seguir en sus puestos en caso de derrota militar y ocupación siempre y cuando su función beneficiase más a la población holandesa que al régimen de ocupación. ${ }^{12}$ Las autoridades de ocupación dieron a los Secretarios Generales más control sobre las capas administrativas más bajas, al igual

\footnotetext{
${ }^{10}$ Jennifer L. Foray, “The 'Clean Wehrmacht' en the German-Occupied Netherlands, 1940-5," Journal of Contemporary History 45 (2010): 769.

${ }^{11}$ Loe de Jong, Het Koninkrijk der Nederlanden in de Tweede Wereldoorlog 4 (La Haya, 1972), pp. 46104; Piet de Rooy, Republiek van Rivaliteiten: Nederland sinds 1813 (Amsterdam, 2002), pp. 3197-198; Johannes Koll, Arthur Seyss-Inquart und die deutsche Besatzungspolitiek in den Niederlanden 1940-1945 (Viena, 2015).

12 Trienekens, "The Food Supply in The Netherlands during the Second World War," en Food, Science, Policy and Regulation in the Twentieth Century: International and Comparative Perspectives, eds. David F. Smith y Jim Phillips (Londres, 2000), 118; Peter Romijn, Burgemeesters in Oorlogstijd: Besturen tijdens de Duitse Bezetting (Amsterdam, 2006), pp. 50-57.
} 
que el derecho de veto y la fuerza de la ley, aunque siempre bajo la supervisión alemana. $^{13}$ Esas tareas de supervisión eran responsabilidad de cuatro Generalkommissare (comisarios generales) alemanes, que a la vez eran representantes del régimen de ocupación y jefes de sus propios departamentos. ${ }^{14}$ En el año 1941, el Comisariado del Reich de Seyss-Inquart daba empleo a 1600 trabajadores, funcionarios y personal de oficina, sin incluir a los agentes de la policía alemana y a otros servicios de seguridad. ${ }^{15}$

De acuerdo con las órdenes de Hitler, la principal prioridad de las autoridades alemanas en los Países Bajos ocupados era sacar el máximo provecho de su economía, tecnología y, llegado el momento, de sus colonias. ${ }^{16}$ Esas prioridades diferían mucho de las de los otros territorios ocupados en el este. Como explicó Voglis: "En Europa occidental la política alemana intentó mantener y adaptar las estructuras de antes de la guerra a las nuevas necesidades con vistas a sacar provecho racional de los recursos, mientras que en el este y sudeste de Europa, la política nazi consistió en requisar la producción agrícola y las materias primas." ${ }^{17}$ Como parte de esta estrategia más sofisticada de explotación, el mayor interés de Alemania era que los expertos holandeses que mejor sabían cómo maximizar la producción agrícola y montar un sistema de racionamiento eficiente permanecieran en sus puestos. Fue por esa razón que, durante la ocupación, la responsabilidad de la provisión de alimentos quedó en las manos de los dos burócratas holandeses de mayor rango, que habían desempeñado un papel clave en los asuntos económicos y agrícolas del país desde la década de los 30: el Secretario General de Asuntos Económicos (jefe del Departamento de Agricultura y Pesca y también del Departamento de Comercio, Industria y Transporte) Hans Max Hirschfeld, y Stephanus Louwe Louwes, Director General de Provisión de Alimentos (Rijksbureau voor de Voedselvoorziening in Oorlogstijd: RBVVO). Fueron ellos los que

\footnotetext{
${ }^{13}$ Werner Warmbrunn, The Dutch under German Occupation, 1940-1945 (Stanford, 1963), p. 37.

14 Eran de Gestión y Justicia (Verwaltung und Justiz; Friedrich Wimmer), Finanzas y Economía (Finanz und Wirtschaft; Hans Fischbock), Seguridad (Sicherheitswesen; Hanss Albin Rauter) y "Asuntos especiales" (besonderen Verwendung; Fritz Schmidt).

15 Warmbrunn, The Dutch under German Occupation, p. 36; Gerhard Hirschfeld, Bezetting en Collaboratie: Nederland tijdens de Oorlogsjaren 1940-1945 in Historisch Perspectief (Haarlem, 1991), pp. 23-24.

16 J.C.H. Blom, "Nazificatie en Exploitatie," en De Organisatie van de Bezetting, eds. Henk Flap and Wil Arts (Amsterdam, 1997), pp. 17-30; Trienekens, Tussen ons Volk en de Honger, 54-63.

${ }^{17}$ Voglis, "Surviving Hunger," 17.
} 
tuvieron que sopesar constantemente los intereses holandeses y alemanes en el área de los alimentos y las políticas de alimentación, también durante el Invierno del Hambre.

El racionamiento en el periodo de guerra fue mayoritariamente una continuación de la organización de racionamiento holandés de antes de la guerra, desarrollado desde 1937 en adelante como anticipo a una nueva posible guerra mundial. La principal diferencia era que las reglas quedaron subordinadas al Departamento de Alimentación y Agricultura Principal alemán (Hauptabteilung Ernährung und Landwirtschaft: E und $L)$, lo que, en la práctica, casi no trastornó las tareas de los funcionarios de alimentación holandeses. ${ }^{18}$ El RBVVO de la guerra de Louwes estaba cimentado sobre la Organización de Crisis Agrícola y el grupo de organizaciones reglamentarias de comercio que surgieron como resultado de esas medidas desde mediados de 1930, lo que significa que Louwes estaba bien familiarizado con todas las figuras principales del sector agrícola. De hecho, la confianza y compromiso de esas organizaciones aumentó durante la ocupación debido a la reputación anti-alemana de Louwes. Incluso se dice que Seyss-Inquart se dirigió a Louwe una vez como "el líder legal de la ilegalidad." 19

También continuaron otras medidas previas la guerra. Los Comisarios Provinciales de Alimentos, nombrados en agosto de 1939, siguieron en funciones para la organización agrícola y para la inspección de sus provincias. La autoridad local sobre cada distrito de racionamiento, que se solapaba en su mayoría con los límites municipales, siguió en manos de funcionarios locales. La Oficina Central de Racionamiento anterior a la guerra siguió siendo responsable de todo lo relacionado con la asignación de alimentos. Como resultado de esas medidas, el tamaño de la burocracia del sistema alimentario creció enormemente. Incluso sin tener en cuenta los miles de personas que trabajaban para las oficinas de distribución local, durante la ocupación unos 20.000 funcionarios trabajaron en el suministro de alimentos ${ }^{20}$.

Justo después de la rendición a la Alemania nazi, la administración de alimentos holandesa tomó todas las medidas necesarias para mantener el suministro de alimentos

\footnotetext{
18 El Generalkommissar für Finanz und Wirtschaft de Fischböck ejerció la supervisión directa de este.Hauptabteilung. Hasta enero de 1942, el Hauptabteilung se denominaba Geschäftsgruppe Ernährung und Landwirtschaft. Trienekens, Tussen ons Volk en de Honger, pp. 23, 43-4, 53, 68-70.

${ }^{19}$ Ibid., p. 68.

${ }^{20}$ Trienekens, Tussen ons Volk en de Honger, pp. 23, 53, 68-70; Idem, Voedsel en Honger en Oorlogstijd, $39,45,52$.
} 
lo máximo posible. Las reservas de cereales, grasas y forraje que la RBVVO había guardado antes de la guerra, que correspondía a un $80-90 \%$ de la cosecha anual, resultó ser de una valía enorme. Además, como resultado de la pérdida de exportaciones, había un superávit considerable de verduras. No obstante, la falta de alimentos importados siguió requiriendo una transformación agrícola considerable, lo que conllevó una reducción aguda y grave de la población avícola y porcina para guardar cereales para consumo humano. Además, era necesario aumentar los cultivos centrándose en los hidratos de carbono, lo que llevó al aumento del cultivo de patatas y también de centeno y colza. Una gran proporción de la actividad agropecuaria tuvo que pasar de la ganadería a la agricultura, lo que se combinó con la labranza de pastos a gran escala una estrategia que el gobierno holandés también realizó durante la Primera Guerra Mundial. Louwes reflejó con concisión esta transición afirmando que "la alimentación de los holandeses tiene que descender en calidad para que sea más o menos suficiente en cantidad. $^{21}$

El nuevo sistema de racionamiento necesitaba ser redefinido para encajar con las diferentes necesidades biológicas. Un departamento de nutrición especial de la RBVVO creó una clasificación según la edad y profesión para garantizar la asignación de alimentos más justa posible, Los trabajadores que hacían trabajos pesados tenían derecho a raciones considerablemente mayores que las de otros trabajadores adultos, los niños recibían raciones más pequeñas pero con mayor proporción relativa de grasas y proteínas, y las madres jóvenes o embarazadas tenían derecho a más asignación de leche, en particular, al igual que más alimentos de origen animal. Obviamente, en práctica, la asignación dentro del hogar era la que determinaba el consumo individual. También se asignaban raciones suplementarias a los enfermos y a personas que realizaban trabajos perjudiciales para su salud. Las personas mayores no recibían raciones extra porque el ocupante alemán les consideraba "económicamente improductivos." 22 A los agricultores se les permitía consumir parte de su producción y no se les daba cupones para los alimentos que ellos mismos producían, lo que significa

\footnotetext{
${ }^{21}$ Archivos nacionales de La Haya [NA], 2.21.238, inv.no. 117, Informe Louwes, p. 7; M.J.L. Dols y D.J.A.M. van Arcken, "Food Supply y Nutrition in the Netherlands during and immediately after World War II," The Milbank Memorial Fund Quarterly 24 (1946): 327.

22 Stephanus L. Louwes, “De Voedselvoorziening," en Onderdrukking en Verzet II, ed. Johannes J. van Bolhuis (Arnhem, 1950), p. 622.
} 
que las dietas en tiempo de guerra no cambiaron tanto para ellos como para los habitantes en la ciudad. Aun así, la distribución social general de alimentos durante la ocupación alemana era más "justa" que en tiempos de antes de la guerra ${ }^{23}$.

Al igual que en otras regiones de la Europa ocupada, parte de la producción agrícola holandesa cruzó la frontera a Alemania. Las estimaciones aproximadas de antes y después de la guerra afirman que entre un 80 y $90 \%$ de la producción total desapareció hacia el este, lo que encaja perfectamente con la imagen del ocupante alemán que sistemáticamente saqueó los recursos holandeses. Aunque al inicio de la ocupación una gran parte de las reservas holandesas de grasas, café y cacao fueron exportadas a Alemania obligatoriamente, en los años siguientes las exportaciones siguieron siendo relativamente bajas. Las exportaciones reales (en kcal) a Alemania fueron de tan solo un 3,9 por ciento en 1942-43, y de solo un 3,3 por ciento entre 1943-44. Se trataron sobre todo de verduras y semillas. ${ }^{24}$ Las autoridades alemanas presionaron continuamente para aumentar el volumen de importaciones pero la relativa buena relación existente entre los encargados de la alimentación en Holanda y el $E$ und $L$ alemán ayudó a limitar esas exportaciones. ${ }^{25}$ Aunque a partir de 1943 Reichsmarschall Göring exigió cada vez más hombres y materiales holandeses para la economía bélica, las autoridades civiles alemanas estaban menos inclinadas a cumplir esas demandas, centrándose más en mantener las demandas domésticas. Tanto Louwes como Hirschfeld hicieron lo posible para dar a las autoridades civiles alemanas los argumentos necesarios para sus negociaciones exportadoras con Berlín. Las dos estrategias principales que siguieron para minimizar las exigencias de exportación fueron mantener las raciones oficiales en los Países Bajos por debajo de las alemanas y declarar la producción agrícola por debajo de las cifras reales ${ }^{26}$.

\footnotetext{
${ }^{23}$ George C.E. Burger et al. eds., Malnutrition and Starvation in Western Netherlands: September 1944July 1945, part I (La Haya, 1948), p. 67; Trienekens, “The Food Supply,” 122; Futselaar, Lard, Lice, y Longevity, p. 69.

${ }^{24}$ Trienekens, Tussen ons Volk en de Honger, pp. 201-202. Trienekens, “The Food Supply,” pp. 118-120.

${ }^{25}$ NIOD Institute for War, Holocaust and Genocide Studies [NIOD], 212a, inv.no. 102, Carta de Louwes a Hirschfeld sobre la situación alimentaria, 11 de enero 1944. E und $L$ hace referencia al Ernährung und Landwirtschaft, el Ministerio de Agricultura y Alimentación. Nota de Alejandro Pérez-Olivares.

${ }^{26}$ NA, 2.21.238, inv.no. 117, Informe Louwes, p. 9; Louwes, "De Voedselvoorziening," pp. 615-616; Klemann, Nederland 1938-1948, pp. 493-494.
} 
Esto no significa que el ocupante alemán no interfiriese en el sistema alimentario en detrimento de algunos grupos. Para el año 1944, se estima que 350.000 personas vivían en la clandestinidad en Países Bajos, 16.000 de ellos judíos. La gran mayoría de ellos eran hombres adultos que querían evitar el Arbeitseinsatz ${ }^{27}$. Con tantas personas viviendo en la clandestinidad, el régimen de ocupación alemán empezó a desplegar nuevas estrategias de exclusión. Anteriormente, el deseo alemán de introducir un sistema de racionamiento separado para los ciudadanos judíos fue parado por las autoridades de alimentación holandesas, pero a finales de 1943 fueron incapaces de resistir la demanda alemana de introducir nuevas cartillas de racionamiento. La introducción de esas segundas cartillas de racionamiento (Tweede Distributiestamkaart) fue un intento claro de privar a aquellos que escondían comida. Con esas segundas cartillas de racionamiento, las raciones estaban ligadas a la identificación personal, garantizando que las autoridades alemanas podían hacer de la comida otro arma importante de su sistema general de exclusión y represión. ${ }^{28}$ En respuesta a ello, los grupos de resistencia holandeses tuvieron como prioridades la falsificación de tarjetas de identidad y el robo de centros de racionamiento.

A pesar de la creciente explotación y represión, las preparaciones exhaustivas holandesas para el suministro de alimentos durante la guerra y las avanzadas instituciones de racionamiento que tenían, junto con la importancia secundaria del mercado negro y las relativamente bajas demandas de exportaciones, hicieron que las raciones evitaran una crisis alimentaria seria hasta el otoño de 1944. Si comparamos la situación de Países Bajos con la de otros países europeos en el mismo periodo, las raciones holandeses sólo eran un poco menores que las de Alemania y del Protectorado de Bohemia y Moravia, una indicación clara de que los holandeses mantuvieron una posición relativamente privilegiada entre los otros países ocupados y disfrutaron de un sistema de racionamiento que funcionaba bien. Además, las raciones comparativamente más altas en los Países Bajos también son muestra de que las órdenes explícitas de Hitler de no tratar a los holandeses "germánicos" de forma diferente a los ciudadanos

\footnotetext{
27 "Despliegue laboral", en sentido literal. El Arbeitseinsatz fue el sistema de trabajos forzados establecido para equilibrar la producción tras la llamada a filas de los varones en edad laboral. Nota de Alejandro Pérez-Olivares.

${ }^{28}$ Warmbrunn, The Dutch under German Occupation, p. 13; De Jong, Het Koninkrijk 5, p. 434; Romijn, Burgemeesters in Oorlogstijd, pp. 225-233.
} 
alemanes del Tercer Reich fueron, de hecho, seguidas durante los primeros cuatro años de ocupación. ${ }^{29}$ La mayor parte de los otros territorios ocupados en Europa occidental y oriental tuvieron que aguantar con mucho menos, excepto la autosuficiente Dinamarca ocupada $^{30}$.

No obstante, en 1944 las condiciones cambiantes de la guerra afectaron seriamente al sistema de alimentación holandés. La Wehrmacht no solo demandó el consumo de más comida, sino que como parte de las operaciones militares, restringió la pesca, el transporte e inundó tierras cultivables. ${ }^{31}$ Al mismo tiempo, Alemania exigió más hombres adultos para trabajar en la economía bélica alemana y para reforzar proyectos y, para 1944, aproximadamente 300.000 holandeses se vieron obligados a trabajar en Alemania. ${ }^{32}$ Todas esas medidas negativas se aceleraron tras la liberación de Bruselas y Amberes (3-4 septiembre). El 4 de septiembre, Seyss-Inquart anunció el estado de emergencia (Ausnahmezustand), que básicamente implicó que toda forma de resistencia contra el ocupante se respondería inmediatamente con la fuerza de las armas. El estado de alerta vino acompañado del caos total. El 5 de septiembre, decenas de miles de nacionalsocialistas alemanes y holandeses huyeron del país en lo que pasó a conocerse como el "Martes loco" (Dolle Dinsdag). ${ }^{33}$ Los soldados de la Wehrmacht que quedaban confiscaron los medios de transporte, maquinaria, combustible y alimentos; cualquier cosa que pudiera utilizarse en la esperada batalla por los Países Bajos. Lo que quedaba de la economía holandesas y del sistema de alimentos centralizado se deshizo al instante ${ }^{34}$.

\footnotetext{
29 John Lindberg, Food, Famine and Relief 1940-1946 (Genève, 1946), p. 21; Klemann y Sergei Kudryashov, Occupied Economies: An Economic History of Nazi-Occupied Europe, 1939-1945 (Londres, 2012), p. 380.

${ }^{30}$ Para obtener más información de la Dinamarca ocupada, véase: Futselaar, Lard, Lice and Longevity, pp. 64-87; Mogens R. Nissen, 'Danish Food Production in the German War Economy', en Food and Conflict in Europe in the Age of the Two World Wars, ed. Frank Trentmann y Flemming Just (Basingstoke, 2006), pp. 172-92.

${ }^{31}$ De Jong, Het Koninkrijk 10a, p. 55; Trienekens, Tussen ons Volk en de Honger, p. 46.

${ }^{32}$ Ben A. Sijes, De Arbeidsinzet: De Gedwongen Arbeid van Nederlanders in Duitsland (2nd ed., La Haya, 1990), pp. 6, 624.

${ }^{33}$ De Jong, Het Koninkrijk 10a, pp. 57, 175-176, 180-204; Romijn, Burgemeesters in Oorlogstijd, p. 571.

${ }^{34}$ NIOD, 216h, inv.no. 87, Acta de reunión de RBVVO, 9-10 Sept. 1944; Ibid., Notas de prensa, 7-9 Sept. 1944; NA, 2.21.238, inv.no. 117, Informe Louwes, p. 16.
} 


\section{EL HAMBRE COMO ARMA}

¿Por qué afectó la hambruna a los Países Bajos? Teniendo en cuenta que la crisis afectó a uno de los países más desarrollados de Europa, la explicación más lógica es que la escasez de alimentos y la hambruna consiguiente en el oeste de los Países Bajos ocupados fue producto de la guerra total. Al igual que en otras hambrunas acaecidas por el régimen Nazi, como la del gueto de Varsovia en 1940-42, la de la Grecia ocupada en 1941-44 y la del Leningrado sitiado en 1941-44, la guerra no sólo fue la causa principal, sino también la razón principal de que no fuese posible evitar o aliviar la hambruna a tiempo. ${ }^{35}$ Sin embargo, identificar la guerra y la ocupación enemiga como la causa subyacente sigue sin explicar exactamente qué ocurrió en los Países Bajos ocupados durante los últimos meses de guerra - o más importante aún - ni aclara quién o qué fue responsable de la escasez que rápidamente derivó a condiciones de hambruna.

Se podría argumentar que el momento decisivo en la cadena de eventos que llevó a la hambruna en los Países Bajos fue la Operación Market Garden, la mayor operación aerotransportada aliada hasta la fecha, realizada el 17 de septiembre de 1944. Liderada por el Mariscal de Campo Bernard Montgomery, Market Garden pretendía cercar el corazón industrial de Alemania, Ruhr, a la vez que conseguir una liberación rápida de los Países Bajos. Al principio parecía que todo iba acorde con el plan, ya que los aliados consiguieron tomar los puentes holandeses en los ríos Waal y Maas. Pero la ofensiva en el río Rin, cerca de la ciudad de Arnhem, mostró que el puente era "realmente lejano" 36 . Los alemanes contraatacaron y el día 25 de septiembre las últimas tropas aliadas tuvieron que retirarse de Arnhem. ${ }^{37}$ La operación Market Garden había fracasado, y las provincias septentrionales permanecieron ocupadas hasta la primavera de 1945. En los meses siguientes, la gente de la parte aún ocupada del país sufrió las

\footnotetext{
${ }^{35}$ Devereux, Theories of Famine, 148; Voglis, "Surviving Hunger," 16-41.

${ }^{36}$ En la version original en inglés, "proved to be the proverbial «bridge too far»", en referencia al título de la película que en España se tradujo como Un puente lejano (1977). La película se basa en el libro homónimo de Cornelius Ryan, conocido periodista y escritor de libros de divulgación sobre historia militar. Nota de Alejandro Pérez-Olivares.

${ }^{37}$ Dwight D. Eisenhower, Eisenhower's Own Story of the War: The Complete Report by the Supreme Commander General Dwight D. Eisenhower on the War in Europe form the Day of Invasion to the Day of Victory (Nueva York, 1946), pp. 67-8; J.J. Gulmans, 'Operatie Market Garden', en De Bevrijding van Nederland, 1944-1945: Oorlog op de Flank, eds. Christ Klep y Ben Schoenmaker (La Haya, 1995), pp. 118-24; 137-49; Antony Beevor, Arnhem: The Battle for the Bridges, 1944 (Londres, 2018).
} 
consecuencias de perder tres provincias productoras de alimentos además de su única zona minera nacional (véase ilustración 1).

\section{Ilustración 1. Las zonas ocupadas y liberadas a principios de 1945 - zonas urbanas} de provincias occidentales en gris oscuro.

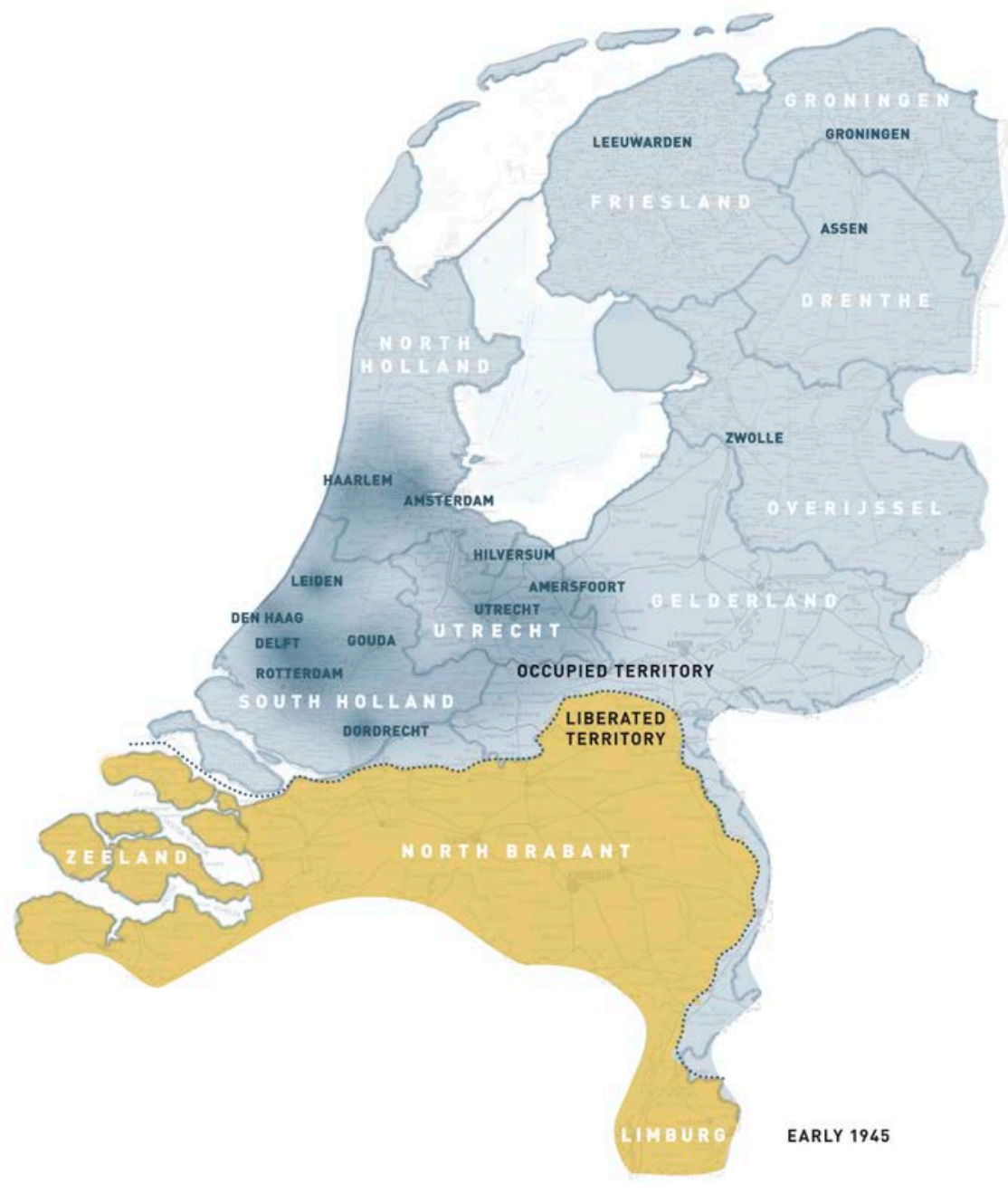

Ilustración de Studio Christa Jesse @ Ingrid de Zwarte

Para poder dar apoyo a los esfuerzos bélicos aliados y socavar las actividades militares alemanas, el 17 de septiembre el gobierno holandés en el exilio en Londres aceptó la petición aliada de anunciar una huelga ferroviaria nacional, lo que resultó en el cese del tráfico ferroviario hasta la liberación en mayo de $1945 .{ }^{38}$ Debido a la huelga, el suministro de alimentos a la zona ocupada dependió de repente del transporte fluvial y

\footnotetext{
${ }^{38}$ A.J.C. Rüter, Rijden en Staken. De Nederlandse Spoorwegen in Oorlogstijd (La Haya, 1960), pp. 227-
} 35. 
por carretera. Esta transición no fue sencilla. El sesenta por ciento del transporte de carbón había dependido totalmente hasta entonces de las vías férreas y un porcentaje parecido de productos perecederos, como las patatas, siempre había sido transportado por ferrocarril. ${ }^{39}$ Para añadir a la confusión reinante, el momento no podría haber sido peor. En septiembre, el uso anual de bienes debería haber sido compensado con la nueva cosecha de patatas. Además, las autoridades alemanas asediadas seguían confiscando todos los medios de transporte, además de los alimentos y el combustible. A esas dificultades hay que añadir el hecho de que el ocupante había usado mucha de la tierra agrícola para la construcción de aeródromos y fortificaciones militares, o había inundado tierra cultivada valiosa para retrasar el avance aliado. Como resultado, las áreas ocupadas tenían escasos alimentos, suficientes para unas pocas semanas de racionamiento. ${ }^{40} \mathrm{~A}$ la vez, los oficiales holandeses tenían que lidiar con las enormes dificultades de transportar esos suministros desde el noreste agrícola a los consumidores en el oeste, habitado por 4,3 millones de personas - 2,6 millones de los cuales vivían en grandes centros urbanos. ${ }^{41}$

El ocupante alemán respondió a la huelga ferroviaria con amenazas y violencia. El representante alemán (Beauftragte) para el ferrocarril dio al Consejo de Ferrocarriles Holandeses un ultimátum: los huelguistas tenían que retomar sus funciones en un plazo de una semana o tomarían presas a sus familias. Si no estaban, la Wehrmacht quemaría sus casas y se llevarían cautivos a otros civiles. Al mismo tiempo, los responsables holandeses de alimentación, Hirschfeld y Louwes, recibieron aviso del cuartel general de Seyss-Inquart de que si la huelga continuaba, el ocupante cortaría todo el suministro de alimentos a las ciudades occidentales, confiscaría lo que quedara almacenado y cerraría todas las tiendas al público. El viernes 22 de septiembre, la Wehrmacht cumplió su palabra y destruyó las instalaciones del puerto de Ámsterdam. ${ }^{42}$ Un comunicado simultáneo desde la agencia de prensa ANP, controlada por los alemanes, avisó a los

\footnotetext{
${ }^{39}$ Rüter, "De Nederlandse Spoorwegen," in Onderdrukking en Verzet IV, pp. 635-636.

${ }^{40}$ NA, 2.21.238, inv.no. 117, Informe Louwes, p. 17; NIOD, 212a, inv.no. 160, "The liberation of the West of the Netherlands." Véase también: Moore, "The Western Allies and Food Relief to the Occupied Netherlands, 1944-1945," War \& Society 10 (1992): 108-109.

${ }^{41}$ Centraal Bureau voor de Statistiek, Jaarcijfers voor Nederland 1943-1946 (Utrecht, 1948), p. 5.

42 NIOD, 216h, inv.no. 162, Nota de Hirschfeld de la reunión con Von der Wense, 23 Sept. 1944; Ibid., De Jong, Het Koninkrijk 10b, pp. 7-13.
} 
huelguistas de las consecuencias de esa "hambruna auto-impuesta". ${ }^{43}$ La amenaza de una hambruna había sido lanzada para resquebrajar la resistencia holandesa.

E1 22 de septiembre, el encargado de $E$ und $L$, Jürgen von der Wense, llamó a Hirschfeld y Louwes para una consulta de urgencia a petición de Seyss-Inquart. Von der Wense, que había tenido una buena relación con los responsables holandeses durante la ocupación, expresó su preocupación por el futuro de los ciudadanos de las urbes occidentales. Durante un debate acalorado, reveló que había serias disputas entre los civiles alemanes y las autoridades alemanas sobre las amenazas de Seyss-Inquart relativas a un embargo del transporte y de que era responsabilizad de los responsables de los alimentos acabar con la huelga. Pero Louwes e Hirschfeld argumentaron que los holandeses siempre se habían comportado de una forma ejemplar durante la ocupación pero que ahora habían entrado en una nueva fase de la guerra. Ambos afirmaron que, dado el grave trastorno de las infraestructuras en combinación con los bombardeos aliados antes del 17 de septiembre, el tráfico ferroviario no iba a ser factible de todas formas. Además, dijeron que fueron los aliados los que habían convocado la huelga y por lo tanto debían ser ellos los que la acabaran. Hirschfeld y Louwes apuntaron que nunca se habían abstenido de tener debates difíciles durante la ocupación y que desconvocar la huelga conllevaría una pérdida de legitimidad inmediata en sus puestos. Y de esa forma, se negaron ${ }^{44}$.

E1 27 de septiembre de 1944, el Reichskommissar Seyss-Inquart tomó represalias cortando todo el transporte de alimentos del noreste al oeste. Este embargo de todo el transporte fluvial fue acompañado de la confiscación masiva de medios de transporte, barcos, combustible y alimentos. Para trastornar más aún la comunicación en las zonas ocupadas, la Wehrmacht cesó los servicios de correos, telégrafo y teléfono. Además de los puertos de Ámsterdam, los alemanes volaron tres kilómetros de muelles en el puerto de Rotterdam, aunque esto se hizo en contra de la opinión del almirantazgo alemán en los Países Bajos. Los grandes navíos fueron hundidos en ambas ciudades para bloquear cualquier posible ruta ${ }^{45}$.

\footnotetext{
${ }^{43}$ NIOD, 212a, inv.no. 164, Nota de prensa ANP Dittmar, 22 Sept. 1944.

${ }^{44}$ Ibid., inv.no. 162, Nota Hirschfeld.

${ }^{45}$ NIOD, 001, inv.no. 656, Kriegestagebuch Marinebefehlshaber Vizeadmiral Stange, Sept. 1944.
} 
Las noticias del embargo alemán llegaron rápidamente al gobierno holandés, el cual tuvo un debate serio sobre la continuación de la huelga ferroviaria. Con la pérdida de la batalla de Arnhem de repente la huelga ya no tenía tanto valor. Aún más importante, el impacto de la huelga en el transporte alemán era ya muy limitado. Willem Albarda, ministro de gestión del agua y transporte en Londres se inclinaba por interrumpir la huelga pero su colega el ministro de guerra Lidth de Jeude recordó al consejo que no estaba en su mano tomar esa decisión. La decisión debía dejarse al Cuartel General Supremo de la Fuerza Expedicionaria Aliada (SHAEE, por sus siglas en inglés) que era quien había dado la orden. El cuartel general aliado indicó que la huelga ferroviaria en el oeste de los Países Bajos podía desconvocarse pero que era imperativo que siguiese al este de la línea entre Arnhem-Apeldoorn por cuestiones militares. No obstante, el gobierno holandés afirmó que era casi imposible la reanudación parcial de los trabajadores porque eso llevaría a más medidas de represalia por parte de los alemanes. Aunque Seyss-Inquart afirmó que se abstendría de perseguir a los huelguistas, los ministros holandeses temían las represalias alemanas y fue su razón para mantener la huelga, por lo que, el 2 de octubre de 1944, el gobierno en exilio pidió la continuación de la huelga ferroviaria ${ }^{46}$.

La falta de confianza del gobierno sobre las intenciones alemanas se debía no solo a las demoliciones y confiscaciones, sino también a la creciente represión en las zonas ocupadas. Un día antes de que Londres pidiese la continuación de la huelga, el Wehrmachtbefehlshaber Christiansen ordenó una redada en la ciudad de Putten (Gelderland) como represalia por un ataque a agentes alemanes de la Wehrmacht por parte de un grupo local de resistencia, que acabó con la muerte de un agente alemán. Ejecutaron en el momento a seis hombres y una mujer joven y otros 659 hombres de Putten fueron deportados al campo Amersfoort, 601 de los cuales fueron más tarde deportados al campo Neuengamme. De los 601 originales, solo sobrevivieron $49^{47}$.

Las limitaciones de tráfico ferroviario y transporte fluvial fueron devastadoras para el suministro de alimentos. Para empeorar las cosas, la creciente escasez de combustible causaban la desconexión de la electricidad y gas para uso residencial en

\footnotetext{
${ }^{46}$ Rüter, Rijden en Staken, pp. 257, 276-280.

47 De esos 49 supervivientes, cinco murieron poco después del fin de la guerra. Madelon de Keizer, Putten: De Razzia en de Herinnering (Amsterdam, 1998).
} 
octubre y noviembre de forma a ahorrar combustible para los servicios económicos vitales. ${ }^{48}$ Sabiendo que privar de esas necesidades básicas llevaría al caos social, el ocupante alemán pronto limitó algunas de sus medidas de represalia más extremas. Más concretamente, fue el Wehrmachtbefehlshaber Friedrich Christiansen quien anticipó con miedo que la hambruna general en el oeste urbano causase disturbios, revueltas y enfermedades, algo que el ejército alemán temía mientras combatía a los aliados en el sur del país. "Problemas en la retaguardia" era lo que menos deseaba Christiansen ahora que los Países Bajos se habían convertido en un campo de batalla activo ${ }^{49}$.

Presionado por la Wehrmacht, el 16 de octubre de 1944 Seyss-Inquart levantó parcialmente el embargo de transporte. La razón oficial para el levantamiento del embargo de transporte era que las autoridades alemanas quería salvar la cosecha de patata de las provincias del noreste. Las autoridades alemanas hasta liberaron a unos 7000 hombres holandeses que habían estado trabajando obligados en los proyectos de fortificación alemanes del noreste, para que trabajasen en los cultivos de patata. ${ }^{50}$ Tres semanas después, el 8 de noviembre de 1944, Seyss-Inquart levantó totalmente el embargo. En ese momento, las circunstancias no habían llevado aún a una hambruna en toda regla. No obstante, otros factores exacerbaron la situación alimentaria, como se describe en la siguiente sección. Durante el juicio de Núremberg, el antiguo Reichskommissar afirmó que la intención del embargo siempre había sido una medida temporal para poner fin a la huelga ferroviaria y que nunca se planeó imponer la hambruna a la población holandesa. Según Seyss-Inquart, la culpa recaía en la Wehrmacht: "En la práctica, el tráfico nunca fue interrumpido por el embargo sino, y creo que los testigos podrían confirmarlo, que se debía a la confiscación de barcos [por la Wehrmacht]" 51 .

\footnotetext{
${ }^{48}$ De Jong, Het Koninkrijk 10b, pp. 25-8.

49 NIOD, 212a, inv.no. 162. Véase también: J. Ravesloot, De Houding van de Kerk in de Bezettingstijd, 1940-1945 (s.1., 1946), p. 30; Informe final de Central IKB, 1945; transcripción en: P.V.J. van Rossem, Het ontstaan van het Inter Kerkelijk Bureau en zijn organisatie (Amsterdam, 1984), pp. 52-61; Telegrama secreto Fock en Londres, 17 Nov. 1944, Nieuwe Rotterdamsche Courant, 23 abril 1955; transcripción en: Ibid., p. 2.

${ }^{50}$ NIOD, 212a, inv.no. 117, Informe reunión departamento de comercio e industria, 16 Oct. $1944 .$.

${ }^{51}$ NIOD, 458, inv.no. 25, p. 11431. Véase también: Ibid., pp. 11493, 11499-11500.
} 


\section{RESTABLECER Y CENTRALIZAR EL SISTEMA ALIMENTARIO}

Después de que Seyss-Inquart acordase levantar el embargo del transporte, se reanudó el diálogo entre los administradores holandeses y alemanes. Debido al cambio en el interés militar alemán que dictó evitar los disturbios y enfermedades, ambas partes se unieron de repente en el deseo de salvar la cosecha de patata. No obstante, los empresarios y alcaldes holandeses no confiaron inicialmente en los motivos alemanes para reanudar las negociaciones, y temían que la campaña de la patata fuese un señuelo para que los trabajadores se incorporasen a los trabajos forzados. Pero Von der Wense consiguió convencerlos de que cooperar iba en el interés del país, de que los hombres trabajarían solo en el suministro de comida y de que a cambio recibirían autorización para no ir a trabajar, al igual que comida, alojamiento, salario y cupones de racionamiento extra. ${ }^{52}$

A pesar de un inicio prometedor, las respuestas del gobierno holandés en el exilio y de la resistencia organizada frustró la campaña. ${ }^{53}$ Londres afirmó que, tras el embargo alemán y la destrucción de las vías terrestres y fluviales, era imposible cooperar una vez más con el régimen de ocupación. El 19 de octubre, el gobierno proclamó sus miedos mediante Radio Orange - la retransmisión holandesa del servicio europeo de la $\mathrm{BBC}$ - diciendo que iban a usar a los trabajadores para trabajos forzados y que era un truco para acabar con la huelga ferroviaria. Las ofertas de trabajadores cayeron inmediatamente casi al cero, y dos tercios de los que ya se habían inscrito renunciaron. ${ }^{54}$ Con la escasez de alimentos creciendo por momentos, al final algunos grupos de resistencia reconocieron que quizás habían juzgado mal la situación. ${ }^{55} \mathrm{La}$ campaña se reinició, pero obviamente, había perdido su empuje.

Además de la oposición holandesa, el uso de redadas masivas alemanas contra varones adultos en las provincias occidentales trastornó aún más la organización del suministro de alimentos, lo que aumentó la falta de confianza entre la población hacia

\footnotetext{
52 NIOD, 212a, inv.no. 117, Circular RBVVO, Oct. 1944; Ibid., inv.no. 167, Diary Hirschfeld, 18 Oct. 1944; Hans M. Hirschfeld, Herinneringen uit de Bezettingstijd (Amsterdam, 1960), pp. 150-151.

${ }^{53}$ NIOD, 212a, inv.no. 117, Mensaje a Hirschfeld, 20 Oct. 1944.

${ }^{54}$ Ibid., Mensaje del gobierno, 19 Oct. 1944.

55 Ibid., ‘Aardappelrooien', Trouw, Oct.1944.
} 
las autoridades alimentarias holandesas. ${ }^{56}$ En línea con la estrategia de Berlín de "retirada del servicio militar con el enemigo" (Entziehung vom Wehrdienst beim Feind), la Wehrmacht procuró eliminar todos los hombres "capaces" - aproximadamente 600.000 en el oeste - obligándoles a trabajar para los esfuerzos militares alemanes ${ }^{57}$. E1 11 de noviembre de 1944, tres días después de que Seyss-Inquart levantase el embargo, la Wehrmacht reunió a 52.000 de los 70.000 hombres con edades entre 17 y 40 en las ciudades de Rotterdam y Schiedam y envió a casi todos ellos a Alemania ${ }^{58}$. El 21 de noviembre, le siguieron redadas en La Haya, Voorburg y Rijswijk. Esa vez, los alemanes consiguieron capturar "solo" 13.000 hombres porque muchos se escondieron. Un día después, Louwes y Hirschfeld se reunieron con el comandante Modrow de la Wehrmacht y con otros oficiales alemanes en la Beauftragte de Seyss-Inquart para La Haya y la provincia de Holanda del sur, casa de Ernst Schwebel. Los oficiales holandeses afirmaron que estaban en un callejón sin salida y la única solución para evitar la hambruna era exonerar a los miles de hombres que se habían ocultado. Los oficiales de la Wehrmacht lo veían difícil de aceptar, pero Schwebel y Modrow reconocieron que el sistema de racionamiento estaba a punto de colapsar y aceptaron a regañadientes ${ }^{59}$.

Esas redadas dañaron considerablemente la situación de la administración holandesa de alimentación. Los transportistas se ocultaron y los agricultores retuvieron los suministros, prefiriendo vender sus productos en el mercado negro o ilegal o a la gente que viajaba al campo en busca de comida. Ligado a la cuestión de la legitimidad estaba también el crecimiento exponencial del comercio clandestino. Aunque era una parte integral de la economía diaria durante la ocupación, el mercado negro no jugó un papel importante en los Países Bajos hasta la crisis alimentaria. Antes del otoño de 1944, entre el 20 y el 25 por ciento de la producción agrícola acabó en el mercado negro, el 10 por ciento de toda la producción económica. En casi todos los otros países

\footnotetext{
${ }^{56}$ NA, 2.11.30.05, inv.no. 2, Informe semanal 20-25 Nov. 1944.

${ }^{57}$ NIOD, 458, inv.no. 23, Juicio de Núremberg a Seyss-Inquart, 10 junio 1946, p. 11408. Sijes, De Arbeidsinzet, p. 540; De Jong, Het Koninkrijk 10b, pp. 96-110.

${ }^{58}$ Sijes, De Razzia van Rotterdam: 10-11 noviembre 1944 (La Haya, 1951).

${ }^{59}$ NIOD, 212a, inv.no. 167, Diario Hirschfeld, 22 noviembre 1944.
} 
ocupados de Europa, ese porcentaje era mucho mayor ${ }^{60}$. No obstante, durante la crisis, el mercado negro se volvió un gran problema para las autoridades. Por ello, la tarea era doble: diseñar un sistema de racionamiento centralizado nuevo en colaboración con las autoridades alemanas y buscar la confianza y compromiso de todas las partes involucradas en la producción y transporte de los alimentos.

Movilizar el transporte era clave para restablecer el sistema de racionamiento, pero resultó ser increíblemente difícil con el decomiso militar alemán, los transportistas escondidos, las políticas locales de alimentación afectadas y con la creciente escasez de combustible. El 1 de diciembre Hirschfeld y Beauftragte Schwebel tuvieron una reunión extensa en la que debatieron los fracasos del Departamento de Gestión de Aguas, oficialmente responsable de los transportes de alimentos. Después Schwebel presentó el caso ante Seyss-Inquart, quien acordó instalar un nuevo comité responsable de todo el transporte en aguas interiores. El 5 de diciembre, Hirschfeld se reunió con Louwes, con los alcaldes de Ámsterdam y Rotterdam y con representantes de Gestión del Agua. Como resultado de la reunión se fundó la empresa "Transporte Central para el Suministro de Alimentos" (Centrale Reederij Voedselvoorziening: CRV), que incluiría el transporte fluvial en los Países Bajos ocupados y se convertiría en el núcleo del sistema de racionamiento central ${ }^{61}$.

Seyss-Inquart aprobó oficialmente el establecimiento del CRV el 11 de diciembre, seguido tres días después por la primera reunión privada entre Hirschfeld y el Reichskommissar. La reunión del 14 de diciembre fue un punto de inflexión en la crisis alimentaria ya que fue la primera indicación clara de que las autoridades civiles alemanas habían cambiado sus políticas en favor del aprovisionamiento alimentario. Este gesto confirmó la sensación de responsabilidad para evitar la hambruna. Esta reunión fue importante porque fue donde Seyss-Inquart sugirió por primera vez la posibilidad de "neutralizar" los Países Bajos occidentales, dando pie a pensar que esta región se designaría como lugar libre de luchas. Hirschfeld escribió en su diario de guerra sobre la reunión lo siguiente: "Hay que decir que el Dr. Seyss-Inquart ha

\footnotetext{
${ }^{60}$ Klemann and Kudryashov, Occupied Economies, p. 269; Klemann, Nederland 1938-1948, pp. 211-217, 548-553.

${ }^{61}$ NIOD, 212a, inv.no. 167, Diario Hirschfeld, 29 de noviembre y 5 de diciembre 1944; Hirschfeld, Herinneringen uit de Bezettingstijd, pp. 154-5; Idem, 'De Centrale Reederij voor de Voedselvoorziening', Economie 10 (1946): 5-7.
} 
mencionado el asunto con cautela y ofreció su asistencia para evitar o aliviar la hambruna que nos amenaza. La facción alemana también se siente responsable." ${ }^{62}$ Le siguieron otras reuniones importantes entre las autoridades civiles alemanas, los responsables holandeses de alimentación y representantes de las industrias organizadas, en las cuales Seyss-Inquart expresó opiniones parecidas. Durante esas reuniones, también debatieron la posibilidad de que barcos holandeses recogiesen carbón de Alemania al igual que ayuda alimentaria por parte de Cruz Roja Internacional ${ }^{63}$.

Los esfuerzos del CRV tuvieron un éxito considerable. Durante un periodo de 25 semanas, la empresa transportó 170.000 toneladas de comida (excluyendo los envíos de la Cruz Roja como se verá más adelante), de los que cuatro quintos eran patatas, representando $1,3 \mathrm{~kg}$ de patatas semanales por persona de las provincias occidentales. ${ }^{64}$ No obstante, las circunstancias adversas de la guerra hicieron imposible que la empresa funcionase a pleno rendimiento. Para empezar, la Wehrmacht y Kriegsmarine alemanas siguieron requisando durante la hambruna. Aunque la escasez aumentaba cada día que pasaba, entre el 30 de octubre y el 14 de diciembre de 1944, 1931 vagones llevando 28.216 toneladas de patatas cruzaron la frontera a la Alemania occidental, casi 50.000 toneladas las siguieron durante los meses clave de hambruna de enero y febrero de 1945. ${ }^{65}$ La creciente rigidez de la regulación y vigilancia alemanas también contribuyeron a ralentizar el trasporte de alimentos ${ }^{66}$.

En segundo lugar, los ataques aéreos contra los navíos no solo causaban miedo entre los transportistas, sino que además dañaron un gran número de navíos. ${ }^{67}$ Un tercer factor fueron las heladas invernales (23 de diciembre 1944-30 de enero 1945) y sus efectos en el transporte. Debido a que la Wehrmacht y Kriegsmarine habían confiscado un gran número de navíos y barcos remolcadores, había poca actividad de transporte

\footnotetext{
62 Ibid., 15 Dec. 1944. Hirschfeld confirmó este cambio de actitud durante los juicios de Núremberg: NIOD, 458, inv.no. 27, 14 de junio 1946, pp. 11686, 11696.

${ }^{63}$ Ibid., inv.no. 167, Diario Hirschfeld, 16-22 de diciembre 1944. Véase también: De Jong, Het Koninkrijk 10 b, pp. 1228-1231.

${ }^{64}$ Hirschfeld, "De Centrale Reederij," p. 10; Población el 31 de diciembre1944. CBS, Jaarcijfers voor Nederland 1943-1946, p. 14.

${ }^{65}$ NIOD, 039, Nota $E$ und $L$ sobre el consumo de patatas, 16 diciembre 1944; Ibid., Geschäftsabteilung der Hauptvereinigung der deutschen Kartoffelwirtschaft, 19 febrero 1945.

${ }^{66}$ NIOD, 216h., inv.no. 312, Informe CRV, 12 de enero 1945.

${ }^{67}$ Ibid., inv.no. 313, Informe semanal CRV 18-24 marzo 1945.
} 
para mantener las vías abiertas. La mayor parte de las rutas se helaron y solo algunos pocos puertos de interés para la Kriegsmarine continuaban navegables en enero. ${ }^{68}$ Las heladas ralentizaron las importaciones, llegando a su casi total interrupción la última semana de enero. Ese mes, las raciones oficiales cayeron en aproximadamente $500 \mathrm{kcal}$ por persona en el oeste, lo que llevó a un mayor número de muertes por hambruna. ${ }^{69}$ Llegado ese momento, las autoridades civiles alemanas, al igual que la policía y el servicio de seguridad (Sipo und SD) en los Países Bajos, hablaron de "hambruna" (Hungersnot) y "situación de emergencia" (Notlage) en sus conversaciones con Berlín sobre la situación en las provincias occidentales ${ }^{70}$. Finalmente, la mayor escasez de combustible puso mayor presión en el transporte de alimentos. Para marzo, casi no quedaba combustible para mantener servicios esenciales como las estaciones de bombeo y los comedores sociales, mucho menos como para que siguiese el transporte de alimentos. ${ }^{71}$ Los últimos trenes con carbón alemanes llegaron al oeste a finales de marzo. Para mediados de abril, el transporte de alimentos había finalizado.

En los primeros meses de 1945, la centralización se convirtió en la principal prioridad de las autoridades civiles alemanas. En una reunión privada el 7 de enero, Seyss-Inquart prometió priorizar la recuperación de la autoridad holandesa en la parte occidental y afirmó una vez más que neutralizar el oeste podría ser la solución para algunas de las dificultades políticas y militares. Para combatir la desintegración administrativa, Seyss-Inquart le cedió a Hirschfeld poderes sobre el departamento de Transporte, nombró al alcalde de Rotterdam, el nacionalsocialista Frederik Müller, Jefe de Asuntos Internos en las tres provincias occidentales y autorizó al presidente del sector empresarial Herman Woltersom como representante formal de las industrias organizadas. No existía jerarquía entre ellos tres, y sus encuentros dejaron al lado la política bélica. A partir de enero, Seyss-Inquart y Hirschfeld se reunían semanalmente

\footnotetext{
${ }^{68}$ Ibid., Report CRV, 24 enero 1945; Hirschfeld, "De Centrale Reederij,” pp. 1-2.

${ }^{69}$ Véase, por ejemplo: NIOD, 216h, inv.no. 313, informe reunión CRV, 15 Feb. 1945; Ibid., 212a, inv.no. 167, Diary Hirschfeld, 5 feb. and 19 marzo 1945.

${ }^{70}$ Bundesarchiv Berlin Lichterfelde [BA], NS 19, 2429, Telegrama 10 enero 1945; Ibid., R70NL, 54, Informe de prensa ilegal en los Países Bajos, 6 febrero 1945.

71 Véase, por ejemplo: NIOD, 216h, Informe reunión CRV, 15 febrero 1945; Ibid., 212a, inv.no. 167, Diary Hirschfeld, 5 febrero y 19 marzo 1945.
} 
en La Haya para debatir asuntos urgentes, mientras que el Reichskommissar prefería su cuartel general en Apeldoom porque era "un sitio mejor para hablar" ${ }^{72}$.

Seyss-Inquart también centralizó más su propia administración al dar autoridad sobre la administración civil alemana en las tres provincias occidentales a su Beauftragte para Holanda Meridional y La Haya, Schwebel ${ }^{73}$. Los representantes de Seyss-Inquart continuaron supervisando de cerca a los alcaldes en sus regiones durante los últimos meses de ocupación, incluso echaron a varios de ellos y asignaron nuevos hombres "fiables" para ocupar sus puestos. A pesar de las malas previsiones para la Alemania nazi, una cifra considerable de nacionalsocialistas siguieron solicitando los puestos de alcalde porque se les tenía gran aprecio y porque estaban dispuestos a aceptar esa difícil tarea. Los cambios de gobierno también significaron que se dio más énfasis a las deliberaciones cuasi-corporativas urgentes que a la dirección política. Para algunos alcaldes del NSB, la elección de una gestión más tecnocrática de la crisis y la "buena" gobernanza llegó como un alivio, por lo menos porque sabían que tendrían que rendir cuentas por colaborar con el enemigo tras la guerra ${ }^{74}$.

Tras sus reuniones con Seyss-Inquart en las que se mencionaba el tema polémico de neutralizar el oeste, Hirschfeld consultó a varios oficiales holandeses en posiciones de poder en enero de 1945. Juntos, esos hombres decidieron informar al Consejo de Representantes de Confianza (College van Vertrouwensmannen), los representantes secretos en territorio ocupado del gobierno holandés en el exilio, quienes informaban a Londres. Sin embargo, en su telegrama a Londres, no hablaron de la propuesta de SeyssInquart $^{75}$. El Consejo, admitiendo tras la guerra que ese había sido "un error político colosal", obvió mencionar la oportunidad presentada por Seyss-Inquart, lo que para este último era un signo de que los aliados no estaban dispuestos a negociar.

${ }^{72}$ BA, R70NL-60, Mensaje SS-Sturmbannführer Wölk, 29 de enero 1945; NIOD, 212a, inv.no. 167, Diary Hirschfeld, 7, 16 de enero 1945; Ibid., inv.no. 114, Acuerdos en casta secreta Hirschfeld, Müller, y Woltersom con Seyss-Inquart tras la reunión del 12 de enero 1945. Véase también: Romijn, Burgemeesters in Oorlogstijd, pp. 596-600.

${ }^{73}$ NIOD, 216h, inv.no. 89, Carta Seyss-Inquart sobre posición de Schwebel a los Secretarios Generales de los departamentos holandeses, 23 febrero 1945.

${ }^{74}$ Romijn, Burgemeesters in Oorlogstijd, pp. 577- 579.

${ }^{75}$ Citado en: De Jong, Het Koninkrijk 10b, p. 1281. 


\section{DESCENTRALIZACIÓN Y DELEGACIÓN}

La crisis también instigó que los responsables holandeses y alemanes actuaran incumpliendo sus políticas habituales de centralización, descentralizando y delegando tareas relacionadas con el suministro de alimentos y permitiendo alguna autonomía. Esas medidas surgieron del hecho de que las autoridades holandesas se enfrentaban al reto de identificar a los más vulnerables de la sociedad mientras sacaban el máximo provecho de los suministros y transporte local. También se emitieron nuevas directivas sobre cómo lidiar con estrategias de superación individuales, como las expediciones de alimentos y un mercado negro creciente. En este sentido, las autoridades civiles alemanas demostraron ser mucho más indulgentes en múltiples ocasiones, debido a las instrucciones militares de evitar disturbios civiles. El comandante de la marina Stange revela esa postura conciliadora en una entrada de enero de 1945 en su diario de guerra. "Es de vital importancia una solución para el problema nutricional (además del humano) para la ocupación alemana, ya que las masas hambrientas y con frío en las grandes ciudades son caldo de cultivo para el Bolchevismo." ${ }^{76}$

La medida de delegación más importante era permitir que un nuevo órgano no gubernamental se ocupase de las responsabilidades de ayuda. Louwes reconoció que ni él ni el RBVVO eran capaces de distinguir entre personas con necesidades y los que no, a nivel individual, y esa era la razón principal para la creación del nuevo órgano. ${ }^{77}$ Además, en otoño de 1944, organizaciones de ayuda locales empezaron a brotar por las áreas ocupadas. Louwes aspiró a coordinar esos esfuerzos locales para mantener algún nivel de control, pero también para recibir aprobación oficial de Seyss-Inquart. A principios de diciembre de 1944, Louwes se reunió con representantes del Consejo Interconfesional de las Iglesias (Interkerkelijk Overleg: IKO). Louwes reconoció la fuerte posición del IKO en la toma de responsabilidad de la ayuda: los ciudadanos confiaban en las iglesias por su postura crítica hacia el ocupante, y la organización también era el vínculo con las comunidades productoras de alimentos en el noreste del país. Además, el IKO podía ser ejemplo de organización "apolítica", que necesitaba el ocupante para esa tarea. El 11 de diciembre, se organizó una reunión a través de Schwebel entre un representante del IKO y Seyss-Inquart, que estuvo de acuerdo con la

\footnotetext{
${ }^{76}$ NIOD, 001, inv.no. 656.

${ }^{77}$ NA, 2.11.30.05, inv.no. 68, Reunión Louwes y Von der Wense, 22 marzo 1945.
} 
incitativa a condición de que solo hubiese un órgano tanto para la ayuda de emergencia como la evacuación de niños. Su aprobación llevó al establecimiento de la Agencia Interconfesional para la Alimentación de Emergencia (Interkerkelijk Bureau voor Noodvoedselvoorziening: IKB), que se convirtió en la única organización con permiso oficial para recopilar alimentos junto con el sistema de racionamiento ${ }^{78}$.

Las autoridades civiles alemanas adoptaron una actitud dual con la IKB y la ayuda de la ONG. Al inicio, Seyss-Inquart alabó abiertamente los esfuerzos de cooperación de las iglesias en la ayuda al oeste del país, incluso elogió a los líderes religiosos a finales de diciembre de 1944, que hicieron un llamamiento a las comunidades durante la misa del domingo para que cooperasen con las autoridades del abastecimiento y condenaran el mercado negro. El Reichskommissar también acordó que la IKB pudiera redistribuir lo que sobraba de los envíos de la Cruz Roja siempre y cuando no interfirieran con el racionamiento central. ${ }^{79}$ Además, la Wehrmacht y la Kriegsmarine alemanas ayudaron en las evacuaciones de niños, ofreciendo espacio vacío en trenes y navíos. El mismo Seyss-Inquart propuso también algunos de los planes de ayuda descentralizados. Por ejemplo, a mediados de marzo de 1945, ofreció traer comida para los niños desde el noreste en vagones enganchados a los trenes de la Wehrmacht. ${ }^{80}$ Tanto las instituciones alemanas como las holandesas encontraron por tanto un punto de convergencia importante centrándose en la ayuda a los niños, lo que seguramente estaba relacionado con la posición social de la juventud en la ideología nacionalsocialista, pero también porque eran una amenaza ínfima a la posición del ocupante en los Países Bajos.

La actitud de Seyss-Inquart hacia la IKB cambió hacia mediados de febrero de 1945, probablemente porque el transporte a través del CRV se reanudó en ese momento. El 16 de febrero, el Reichskommissar ordenó a sus representantes que, debido a la

\footnotetext{
${ }^{78}$ NIOD, 1076, inv.no. 23, Informe de reunión IKO y Louwes, s.n.; Ravesloot, De Houding van de Kerk. Van Rossem, Inter Kerkelijk Bureau, 10. Para obtener más información sobre evacuaciones de niños e iniciativas de alimentación, véase: De Zwarte, 'Coordinating Hunger: The Evacuation of Children during the Dutch Food Crisis, 1945', War \& Society 35 (2016): 132-149; Idem, 'Fighting Vulnerability: Child Feeding Initiatives during the Dutch Hunger Winter', en Societies under Occupation in World War II, pp. 293-310.

${ }^{79}$ BA R70NL-60, Nota de carta de púlipito de las iglesias 7 enero 1945; Ibid., Mensaje Sonderkommando Frank ta Befehlshaber Sipo und SD, 5 enero 1945; NIOD, 212a, inv.no. 167, Diario Hirschfeld, 7 enero 1945; NA, 2.11.30.05, inv.no. 25, Informe de reunión Louwes, Rohde y Schwebel, 21 marzo 1945.

${ }^{80}$ NIOD, 212a, 167, Diario Hirschfeld, 12 marzo 1945.
} 
terrible situación alimentaria, tenían que aplicar medidas más estrictas y vigilancia y que sólo había un único órgano responsable de los alimentos - la RBVVO. Todo otro esfuerzo de ayuda solo tendría éxito si se ocupaba de los excedentes de los agricultores que ya habían entregado su cuota a la agencia de racionamiento central. Como ningún agricultor estaba en esa situación, la condición previa no se cumplía nunca y, como afirmó Seyss-Inquart, esas acciones solo trastornaban y ponían en peligro el suministro general de alimentos. A partir de esa fecha, todos los esfuerzos de ayuda por parte de iniciativas privadas, incluyendo las iglesias, estuvieron oficialmente prohibidas. Alrededor de un mes después, el Reichskommissar también prohibió que las unidades militares ayudaran en la evacuación de niños, incluso si tenían espacio disponible para el transporte de civiles. ${ }^{81}$ Pero Louwes, que temía problemas con los envíos de la Cruz Roja si no había ONG's involucradas para redistribuir los suministros de comida, continuó, con éxito, defendiendo la postura de que ningún otro órgano excepto la IKB pudiese organizar la ayuda, evitando de esa forma una parada prematura en el trabajo de la $\mathrm{IKB}^{82}$.

Las autoridades civiles y militares alemanas no pararon ahí las restricciones y limitaron cada vez más otros tipos de transporte de alimentos. Les inquietaba cada vez más la involucración de grupos de resistencia en el transporte de comida, muy frecuente en todas las zonas ocupadas. Eso les llevó, por ejemplo, a registrar todo el transporte de la Cruz Roja desde noviembre de 1944 en adelante. ${ }^{83}$ La combinación de "corrupción" y provisiones menguantes de alimentos hicieron que Seyss-Inquart impusiera una prohibición de productos a finales de enero de 1945 que dictaba que ningún producto de cereales, legumbres, aceite, queso o mantequilla podía cruzar la línea del río Ijssel de este a oeste. A la prohibición le siguió un decreto del 6 de diciembre de 1944 que prohibía a hombres de entre 17 y 40 años de edad cruzar el IJssel. Las inspecciones las realizaba la policía de fronteras alemana, quien tenía hasta autorización de registrar

\footnotetext{
${ }^{81}$ BA, R70NL-60, Circular Befehlshaber Sipo und SD, 16 febrero 1945; Ibid., Circular Deppner a BdS 17 Feb. 1945; NIOD, 212a, inv.no. 106, Carta Wimmer y Schwebel a Hirschfeld, 12 Feb. 1945; NIOD, 001, Tagesbefehl 10/45, 16 marzo 1945.

${ }^{82}$ NA, 2.11.30.05, inv.no. 68, Reunión Louwes y Von der Wense, 22 marzo 1945.

${ }^{83}$ BA, R70NL-41, Nota Rauter, 2 enero 1945; Ibid.-54, Letter gez. Deppner SS Sturmbannführer to all Einsaitz und Aussenkommandos, policía fronteriza, 20 noviembre 1944.
} 
vehículos de la Wehrmacht en busca de bienes ilegales. ${ }^{84}$ Con el argumento de "la situación de emergencia en las provincias occidentales y el acaparamiento ilegal de las provincias orientales", el decreto también establecía que solo cuatro puertos (Harlingen, Stavoren, Lemmer, y Zwartsluis) tenían permiso para seguir abiertos al transporte de alimentos. Seguía estando permitido el envío a través de vehículos de la RBVVO de paquetes privados de alimentos para familiares o amigos en el oeste ${ }^{85}$.

No obstante, los agentes fronterizos no estaban autorizados a confiscar comida que no iba al mercado negro, ya que eso dependía del Servicio Holandés de Control de la Crisis (Crisis Controle Dienst: CCD), que redirigían los alimentos confiscados de nuevo al sistema de racionamiento. En una circular, el Höhere SS und Polizeiführer ${ }^{86}$ Hanns Albin Raute afirmaba: "Esto evitará la impresión de que las tropas de ocupación alemanas se aprovechan del sufrimiento de las provincias occidentales." ${ }^{87}$ Poco después. el Reichskommissar propuso una prohibición general del transporte de alimentos que no fuese hecho por la RBVVO. Aunque las autoridades de alimentación holandesas tenían dudas sobre la prohibición total acordaron que era necesario acabar con el "transporte salvaje". El 1 de marzo de 1945, se cerraron todos los puentes al paso de civiles y alimentos excepto los que pertenecían a la $\mathrm{RBVVO}^{88}$.

El cierre de los puentes del IJssel hizo que fuese muy difícil para los ciudadanos de la ciudad viajar a las provincias del noreste en busca de comida, popularmente conocido en los Países Bajos como "hongertochten" ("viajes del hambre"). De hecho, el cierre de la línea del IJssel para esos "viajes del hambre” ejemplifica la actitud dual que tomaron las autoridades alemanas hacia esas estrategias de supervivencia individuales. Para empezar, las instrucciones dadas a las unidades militares y de la policía indicaban que, durante la hambruna, se hacía una distinción clara entre la recolección no legal de comida para uso privado y la recolección de comida para el mercado negro. En aras de mantener el orden social, las medidas represoras alemanas contra el mercado negro y el

\footnotetext{
${ }^{84}$ Ibid.-41, Carta gez. Hofmann a Oberkomanndo der Heeresgrupphe H, 31 de enero 1945.

${ }^{85}$ NIOD, 216h, Decisión Hirschfeld sobre el transporte de alimentos que cruzase la línea IJsselline, 29 de enero 1945.

${ }^{86}$ Literalmente, "Jefe superior de policía y de las SS". Nota de Alejandro Pérez-Olivares.

${ }^{87}$ BA, R70NL-41, Circular Rauter, 8 de febrero 1945.

${ }^{88}$ Ibid., 1 de marzo 1945; NIOD, 216h, inv.no.19.
} 
pillaje se endurecieron durante la crisis: no fue rara la ejecución como castigo ${ }^{89}$. Pero por otro lado se toleraban las expediciones por alimentos, a pesar de sus efectos adversos obvios en el racionamiento central.

Al mismo tiempo, se dijo a los agentes de la Wehrmacht que las autoridades holandeses habían ordenado explícitamente a los civiles recoger alimentos del campo y que se castigaría el decomiso no autorizado ${ }^{90}$. Ese cambio de actitud durante la crisis se vio también en el decomiso de bicicletas, un tema muy sensible en la memoria popular holandesa. Mientras que el 16 de octubre de 1944 se dio orden a los agentes de la Wehrmacht de que confiscasen todas las bicicletas de hombres utilizables, una orden del 15 de enero de 1945 dictaba que todo decomiso individual de bicicletas estaba prohibido $^{91}$. Ese mismo mes, el Merkblatt fur die Truppe (Panfleto para las Tropas) afirmaba que el decomiso individual saboteaba el uso sistemático de la tierra y dañaba la reputación de la Wehrmacht y era, por lo tanto, castigado con prisión o incluso muerte. ${ }^{92}$ Eso no quiere decir que algunos soldados u otros oficiales alemanes no requisasen alimentos de civiles para uso personal. Pero esas duras medidas regulatorias y castigos claramente demostraban que el ocupante alemán distinguía bien entre la autoayuda y la usura.

\section{LAS NEGOCIACIONES ENTRE ALEMANIA Y LOS ALIADOS SOBRE AYUDA ALIMENTARIA}

La actitud alemana hacia la ayuda de los aliados para los holandeses hambrientos y su posición en las negociaciones internacionales también dice mucho de sus políticas y toma de decisiones durante la crisis. Durante el Invierno del Hambre, la planificación de ayuda y las estrategias militares demostraron entrar, inevitablemente, en conflicto, al igual que lo habían sido en otras zonas con escasez de alimento de la Europa ocupada. El enfoque aliado se caracterizaba por su deseo de mantener la política de bloqueo ("guerra económica") y evitar cualquier competición internacional por comida. Eso

\footnotetext{
${ }^{89}$ BA, R70NL-41, inv.no. 73, Nota Befehlshaber Sipo und SD en La Haya, 22 de noviembre 1944.

90 NIOD, 001, inv.no. 656, Kriegestagebuch Vizeadmiral Stange, noviembre 1944; BA, R70NL-60, Mensaje Einsatzkommando Rotterdam a Wehrmachtkommandantur, 21 de febrero 1945.

91 BA, R70NL-54, Carta Rauter sobre el decomiso de bicicletas, 16 de octubre 1944; NIOD, 001, Besondere Anordnungen, 15 de enero 1945.

92 Ibid., inv.no. 522, Merkblatt fur die Truppe, 10 de enero 1945. No queda claro si la Wehrmacht de verdad hizo cumplir esas políticas.
} 
significa que la ayuda alimentaria nunca estuvo por encima del objetivo supremo de la victoria militar aliada ${ }^{93}$. De la misma forma, para la Alemania nazi, los parámetros para permitir ayuda neutral o aliada siempre venían dictados por las circunstancias políticas y militares

De hecho, que la ayuda alimentaria supuestamente "neutral" estaba muy politizada quedó absolutamente claro durante las negociaciones entre Alemania y los aliados sobre la ayuda de la Cruz Roja para los territorios ocupados del oeste de los Países Bajos. Ya en octubre y noviembre de 1944, la posibilidad de que llegase ayuda de la Suecia neutral fue ampliamente debatida. Siempre y cuando el gobierno holandés negociase con los suecos, el Gabinete de Guerra Británico no objetaba desde el punto de vista del bloqueo. Desde 1941, habían permitido el intercambio internacional dentro del área de bloqueo lo que permitía a los territorios ocupados comprar comida de países neutrales. ${ }^{94}$ El comandante supremo Dwight D. Eisenhower también aprobó el plan, preocupado de que la escasez de alimentos siguiese aumentando hasta el momento de la liberación, una fecha que le era imposible predecir. El comandante supremo afirmó: "Entiendo que parte de las provisiones de ayuda caerán en manos alemanas, pero acepto ese riesgo. Cualquier ayuda a la población civil holandesa que pueda darse antes de la liberación facilitará los problemas de ayuda tras la liberación" ${ }^{95}$.

Esas consideraciones dejaron a los Jefes del Estado Mayor británicos con cuatro potenciales programas de ayuda, debatidos en Londres el 6 de noviembre de 1944. 1) un barco sueco llevaría provisiones desde Gotemburgo a un puerto holandés, seguramente Ámsterdam; 2) un barco del Comité Internacional de la Cruz Roja (CICR) llevaría cargamento desde Lisboa; 3) las provisiones se arrojarían desde el aire en las tres ciudades principales del oeste de los Países Bajos; 4) una embarcación de la Cruz Roja

\footnotetext{
${ }^{93}$ Joan Beaumont, 'Starving for Democracy: Britain's Blockade of and Relief for Occupied Europe, 19391945', War \& Society 8 (1990): pp. 57-82; Ben Shephard, 'Becoming Planning Minded: The Theory and Practice of Relief 1940-1945', Journal of Contemporary History 43 (2008): pp. 405-19; Hionidou, Famine and Death in Occupied Greece, p. 16; Ronald W. Zweig, 'Feeding the Camps: Allied Blockade Policy and the Relief of Concentration Camps in Germany, 1944-45', The Historical Journal 41 (1998): pp. 825-51. Véase también: Moore, 'The Western Allies'.

${ }^{94}$ The National Archives Kew [TNA], WO 220/668, AMSSO to SHAEF Forward, 6 octubre 1944; Ibid., FO 238/303, Telegrama FO a Estocolmo, 19 de octubre 1944; Beaumont, "Starving for Democracy," pp. 65-66.

${ }^{95}$ National Archives and Records Administration College Park [NARA], 331, Entrada 2, Box 117, Carta SHAEF firmada por Eisenhower a los jefes de estado mayor británicos, 29 de octubre 1944. También se cita en: Moore, “The Western Allies," p. 98.
} 
llevaría las provisiones desde Basilea por el $\operatorname{Rin}^{96}$. En las negociaciones subsiguientes entre los aliados y los alemanes, algunas consideraciones tomaron gran trascendencia para ambas partes. Alemania prefería claramente la última opción: según el SHAEF, eso era porque querían que el Rin fuese navegable por interés propio. El cuartel de los aliados debatió la idea de arrojar desde el aire las provisiones ya que no había garantía de que las provisiones llegaran de hecho a la población civil. No obstante, los aliados sí pensaban que arrojar provisiones de forma simbólica una primera vez tras la liberación sería "esencial" en la guerra psicológica ${ }^{97}$. Las dos primeras opciones parecían aceptables, pero el Gabinete de Guerra Británico consideraba que los envíos de la Cruz Roja desde Lisboa no eran tan positivos debido a las múltiples solicitudes de otros países ocupados por los Nazis ${ }^{98}$. Por lo tanto, la única opción que quedaba en ese momento era considerar detalladamente la ayuda desde la Suecia neutral. Eisenhower aseguró que el SHAEF no veía objeción desde el punto de vista militar. "Parece mejor que los navíos con ayuda lleguen lo antes posible" ${ }^{99}$.

A pesar de un inicio prometedor, no hubo evolución en las siguientes semanas. Poco después, el SHAEF se negó a abrir el Rin para transporte, los alemanes se negaron a que observadores del CICR distribuyeran los suministros suecos en el terreno porque los Países Bajos eran ahora zona de combate y cualquier ayuda debería ser distribuida por la Cruz Roja alemana y holandesa. Aunque eso significase una concesión enorme por parte de los aliados, el secretario de estado para asuntos exteriores Anthony Eden inicialmente apoyó el cambio de planes. No obstante, poco después, se recibió un informe secreto de los Países Bajos que afirmaba que todos los camiones y el combustible perteneciente a la Cruz Roja holandesa habían sido confiscados y sus responsables dimitieron como protesta por el nombramiento obligado de un holandés

\footnotetext{
${ }^{96}$ Ibid., Mensaje SHAEF firmado por Eisenhower a los Jefes de Estado Mayor británicos, 6 de noviembre 1944.

${ }^{97}$ Ibid., Mensaje SHAEF Main G-5 firmado Eisenhower al Cuartel de Guerra, 15 noviembre 1944.

98 TNA, FO 238/303, Mensaje FO firmado W.G. Hayter al Embajador Sir Neville Bland, 9 nov.1944; Ibid., CAB 119/140, COS reunión 27 Oct.-7 Nov.r 1944; Ibid., Carta Ministerio Exteriores a Secretario comité Jefes del Estado Mayor 30 Oct. 1944; Ibid., WO 220/668, Almirantazgo a FO, 26 octubre 1944; Ibid., PREM 3221 11, AMSSO a SHAEF Main, 3 Noviembre1944.

99 NARA, 331, Entrada 2, Box 117, carta SHAEF firmado Eisenhower a Jefes de Estado mayor combinados y jefes de estado mayor británicos, 15 de noviembre 1944. Véase también: TNA, WO 219/1325.
} 
“oficial de la germánica SS”, Carel Piek, como nuevo responsable ${ }^{100}$. Aunque los barcos con ayuda alimentaria en Suecia y Lisboa estaban listos con aprobación de Alemania, los aliados inmediatamente pusieron en espera la ayuda sueca hasta nuevo aviso: no se permitiría la ayuda hasta que hubiera un plan satisfactorio de distribución ${ }^{101}$.

Finalmente, el 19 de enero de 1945 - más de tres meses después de la promesa sueca inicial - los gobiernos alemanes y suecos llegaron a un acuerdo. Dos barcos suecos navegaron seguros desde Gotemburgo hasta el importante puerto holandés de Delfzijl con 5000 toneladas de provisiones, y la distribución posterior la hicieron dos representantes suecos residentes en Países Bajos. Mientras tanto, un barco de CICR cargado con provisiones en Lisboa, estaba también listo para navegar hasta Gotemburgo. Ese cargamento sería retenido por los aliados hasta que recibiesen noticias de la distribución satisfactoria del cargamento sueco ${ }^{102}$. Para los aliados, esta propuesta era muy atractiva, inclusive más porque uno de los representantes suecos llevaba un par de años haciendo trabajo de inteligencia para ellos. Concluir el acuerdo era también favorable para los ocupantes alemanes. No solo querían evitar disturbios sociales y revueltas a corto plazo, los oficiales de alto rango alemanes también habían expresado el miedo de que esas situaciones sociales podrían ser caldo de cultivo para el bolchevismo ${ }^{103}$.

En los meses de febrero a abril de 1945, un total de cinco envíos de la Cruz Roja - tres de Suecia, uno de Suiza y uno del CICR - llegó a los Países bajos occidentales, trayendo aproximadamente un total de 14.000 toneladas de productos de calidad al país, equivalente a cinco kilos de alimento por persona. Además, un tren del CICR con cereales de Rumanía para los Países Bajos se quedó varado en Alemania, por lo que el gobierno alemán aprobó el transporte alternativo de 2.600 toneladas de centeno desde Westfalia $^{104}$. Finalmente, las graves restricciones impuestas en los envíos de la Cruz

\footnotetext{
100 TNA, FO 238/303, Carta R.A. Gallop ta Sir Nevil Bland, 7 de diciembre 1944; Aart W. Wassenaar. Van Winterhulp via Oost-Compagnie en Marseille naar Rode Kruis: De Loopbaan van Carel Piek Voor, Tijdens, en $\mathrm{Na}$ de Bezettingstijd 1940-1945. Een Geschiedenis van Idealisme en Collaboratie (Soesterberg, 2016), pp. 139-145.

${ }^{101}$ BA, NS19/3403, Telegrama Rauter a Berlín, 14 de diciembre 1944.

102 NARA, 331, Entrada 2, Box 118, Carta Jefes e Estado Mayor a SHAEF Main, 19 enero 1945.

${ }^{103}$ NIOD, 001, inv.no. 656, Kriegestagebuch Marinebefehlshaber Vizeadmiral Stange, enero 1945.

${ }^{104}$ United Nations Archives and Records Centre [UN], AG 18-004, S-1245-0000-0769, Declaración sobre Don Suisse, 19 marzo 1945; TNA, ADM 116/5350, Mensaje Norton Berne a FO, 27 marzo 1945; TNA,
} 
Roja frustraron el establecimiento de un programa de ayuda regular, lo que impidió más adelante que la ayuda "neutral" alcanzase su potencial total de aliviar la hambruna.

Las nuevas negociaciones comenzaron en la primavera. A finales de marzo, el Primer Ejército Canadiense y el Segundo Ejército Británico avanzaron en dirección noroeste, liberando con éxito una gran parte del noreste de los Países Bajos. Obviamente, conocedores de su precaria posición, las autoridades civiles alemanas mostraron su disposición a negociar. El 2 de abril de 1945, Seyss-Inquart debatió con Hirschfeld la posibilidad de dejar de lado la orden de Hitler de "tierra quemada" y sacar parte del oeste de Holanda de las actividades militares. Antes de esa reunión, SeyssInquart había dialogado con el ministro alemán de armamento Albert Speer sobre desobedecer la orden del Führer, quien estuvo de acuerdo en que debería evitarse la destrucción total ${ }^{105}$. El Reichskommissar también expresó su interés en contactar con el Consejo de Representantes de Confianza ${ }^{106}$. Este acercamiento iniciado por SeyssInquart no fue único para Holanda. De hecho, varios líderes nazis de alto rango actuaron de forma parecida. Por ejemplo, durante las últimas semanas antes de la inminente derrota alemana, el plenipotenciario del Tercer Reich (Reichsbevollmächtigter) para la Dinamarca ocupada. Werner Best, también luchó contra la ejecución de la orden de tierra quemada ${ }^{107}$. Debemos ver también dentro de este contexto las acciones y la actitud de Seyss-Inquart.

En la tarde del 12 de abril Seyss-Inquart se reunió con representantes del Consejo. El Reichskommissar dio su apoyo total a las labores de ayuda, siempre que la situación militar lo permitiese. Los holandeses mencionaron el asunto de abandonar medidas más destructivas, ahora que Alemania había perdido inevitablemente la guerra, e incluso citaron el Mein Kampf de Hitler y el Vom Kriege de Clausewitz ${ }^{108}$ para

WO 220/668, Almirantazgo a C-in-C's, s.a.; NIOD, 216h, inv.no. 312, Actas CRV 15, 28 Feb. 1945; Ibid., 233b, inv.no. 18, Informe movimientos clandestinos al gobernó holandés, 15 de abril 1945.

105 Gitta Sereny, Albert Speer: His Battle with the Truth (London and Basingstoke, 1995), 456-87; Joachim Fest, Speer: Eine Biographie (Berlin, 1999), pp. 255-7, 264-78.

106 NIOD, 458, inv.no. 27, Audiencia Hirschfeld, 14 junio 1946, p. 11686; NIOD, 212a, Diario Hirschfeld, 2 abril 1945; Meindert Fennema and John Rhijnsburger, Dr. Hans Max Hirschfeld: Man van het Grote Geld (Ámsterdam, 2007), pp. 129-30; Stephen Dando-Collins, Operation Chowhound: The Most Risky, Most Glorious US Bomber Mission of WWII (Nueva York, 2015), pp. 65-70.

${ }^{107}$ Ulrich Herbert, Best: Biographische Studien über Radikalismus, Weltanschauung und Vernunft $1903-$ $1989,\left(5^{\text {th }}\right.$ ed., Bonn, 2011), pp. 398-400.

108 Título original de su famoso libro De la guerra. Nota de Alejandro Pérez-Olivares. 
convencer de su obligación de dejar de combatir en esas circunstancias. Seyss-Inquart informó a los líderes de la resistencia de que la directiva original de destruir todos los bienes capitales no militares durante la retirada había sido eliminada por petición propia tras debatirlo con Speer. Afirmó que solo existía una orden que había que hacer en cualquier circunstancia, la de mantener posiciones en la región costera holandesa hasta que dejase de existir el estado de guerra en Alemania. La reunión finalizó con el entendimiento de que si las tropas aliadas paraban antes de la línea de Grebbe, y no cometían más actos de guerra en la zona costera, los mandos militares alemanes estarían preparados a abandonar cualquier tarea de inundación o destrucción de más áreas o bienes al igual que a dar apoyo a la ayuda humanitaria. Ambos lados acordaron que un acuerdo que pudiera entenderse como una tregua no oficial debería hacerse de la forma más discreta posible ${ }^{109}$.

Cuando Seyss-Inquart recibió preguntas de Londres sobre si estaría dispuesto a trabajar con el General Eisenhower para llegar a más acuerdos, la respuesta fue favorable. El primer ministro británico Winston Churchill había informado al Comandante Supremo sobre la posibilidad de "neutralizar el oeste ocupado", y Eisenhower acordó que parecía una muy buena opción, siempre y cuando no contraviniese el principio de rendición incondicional. Le pidió a Churchill que promoviese el asunto de la forma mencionada lo más rápido posible. Una vez más, los beneficios militaras desempeñaron un papel importante: si se lograba una tregua informal, el SHAEF solo tenía que montar un pequeño ejército en la frontera holandesa, dejando un ejército de mayor tamaño disponible para el movimiento decisivo de Eisenhower en Lubeck ${ }^{110}$.

Siguiendo el plan de arrojar ayuda desde el aire para auxiliar a los holandeses, Eisenhower asignó dos fuerzas de bombardeo estratégicas - el mando bombardero de la RAF y la Octava Fuerza Aérea de EEUU - que, en pruebas, arrojarían las primeras provisiones durante la noche del 25-26 de abril ${ }^{111}$. Seyss-Inquart y el General Johannes

\footnotetext{
109 TNA, PREM 3/221/12, Informe reunión 12 abril, Churchill a Eden, 16 abril 1945; NARA, 331, 2/118, Mensaje fuerzas nacionales holandesas a SHAEF, 14 abril 1945; NIOD, 458, inv.no. 27, Hearing Schwebel, 14 junio 1946, p. 11704; Ibid., inv.no. 24, Juicio Núremberg a Seyss-Inquart, 11 June 1946, p. 11433; Dando-Collins, Operation Chowhound, pp. 72-4.

${ }^{110}$ TNA, PREM 3/221/12, Oficina del ministro de defensa Isman a Churchill, 19 de abril 1945.

${ }^{111}$ NARA, 331, 2/118, Mensaje personal de aire SHAEF a USSTAF, 24 de abril 1945.
} 
Blaskowitz, el nuevo Comandante en Jefe de los Países Bajos del noroeste, respondieron diciendo que estaban de acuerdo en cuestión de principios con la introducción de ayuda alimentaria, pero rechazaron que llegase desde el aire por razones de defensa. Además, el envío desde el aire contribuiría mínimamente a los problemas de alimentación y la distribución no podría controlarse adecuadamente. Seyss-Inquart propuso como alternativa que los alimentos llegasen en barco y tren, y que la distribución la realizase la administración de alimentos holandesa ${ }^{112}$. Debido a la actitud alemana, el SHAEF ordenó la vuelta inmediata de los bombarderos, y pospuso esa misión hasta nuevo aviso ${ }^{113}$. Aunque ninguno de ellos estaba convencido del concepto del envío de ayuda desde el aire, Louwes y Hirschfeld aconsejaron a Seyss-Inquart aceptar los envíos pero solo en cuatro zonas designadas bajo su control. El 26 de abril, las autoridades alemanas acodaron el envío por aire y un día después aceptaron la invitación a reunirse con representantes aliados ${ }^{114}$.

Al día siguiente, Schwebel y uno de los representantes de Blaskowitz cruzaron la línea del frente en Amesfoort y hablaron brevemente con el comandante general Sir Francis de Guingand, del Jefe de Estado Mayor de Montgomery, y otros representantes de los aliados en el pueblo de Achterveld. La primera reunión fue introductoria y se limitó a asuntos relacionados directamente con la introducción de alimento al occidente de Holanda. Se organizó una segunda reunión dentro de las tierras de los aliados dos días después ${ }^{115}$. La intención de Eisenhower había sido comenzar con los envíos de alimentos por aire inmediatamente tras esa reunión, pero su plan se vio frustrado por una tormenta y una niebla devastadora en el noroeste de Europa. Con la mejora del tiempo durante la noche, los primeros bombarderos pesados Lancaster pudieron despegar el domingo 29 de abril por la mañana del aeródromo Ludford Magna de East Midlands. La primera misión de la RAF constaba de 500 toneladas, arrojadas en cuatro

\footnotetext{
112 NIOD, 086, inv.no. 439, Correspondencia Schwebel y Van der Vlugt, 25 de abril 1945.

113 NARA, 331, 2/118, Mensaje Eisenhower a AGWAR y AMSSO, 27 de abril 1945. Véase también: TNA, CAB 119/140; PREM 3/221/12.

114 TNA, PREM 3/221/12, Ministro de defensa de Churchill, 27 de abril 1945. NIOD, 216h, inv.no. 93, 'Report on dropping of food supplies', 12 de mayo 1945; Ibid., inv.no. 93, Mensaje Seyss-Inquart a SHAEF, 25 de abril 1945; Ibid. Telegrama Seyss-Inquart, 27 de abril 1945; NIOD, 212a, inv.no. 147, Nota Seyss-Inquart a Louwes, 27 de abril 1945. NIOD, 086, inv.no. 439, Correspondencia Van der Vlugt y Schwebel, abril-mayo 1945.

115 NIOD, 212a, inv.no. 162, Diario Hirschfeld, 28 de abril 1945; Ibid., 458, inv.no. 27, Audiencia a Schwebel en juicio de Núremberg Seyss-Inquart, 14 de junio 1946, p. 11704.
} 
zonas siguiendo las rutas y otras indicaciones establecidas por el mismo SeyssInquart $^{116}$.

El lunes 30 de abril, hubo una segunda reunión en Achterveld. Esta vez, SeyssInquart estaba presente para hablar con el adjunto de Eisenhower, Bedell Smith, y con otros representantes de los aliados sobre la operación de alimentos y otros aspectos de los planes de ayuda de los aliados. El Reichskommissar Seyss-Inquart estaba acompañado de Schwebel, al igual que de otros altos oficiales de la Armada, del Ejército de Tierra y el de Aire. Los intereses holandeses estaban representados por el Príncipe Bernhard y una delegación de expertos en alimentos y transporte de las zonas ocupadas, incluyendo a Louwes, ya que las negociaciones se limitaban únicamente a política alimentaria. El comandante general Ivan Susloparov había sido asignado en el último minuto para asistir a la reunión como representante soviético. Pronto quedó claro que los delegados alemanes no estaban autorizados a negociar cláusulas militares de la tregua, no pudiendo hacerlo mientras el comandante alemán en los Países Bajos holandeses estuviese en contacto con sus superiores. Por ello la reunión solo trató del suministro de ayuda ${ }^{117}$. Se acordó que las provisiones por aire aumentarían lo máximo posible hasta las 1.550 toneladas por día, con un suministro regular por tierra que empezaría el 2 de mayo y los primeros barcos que llegarían a Rotterdam dos días después ${ }^{118}$. Seyss-Inquart demostró ser totalmente consciente de su responsabilidad en aligerar la carga de los holandeses, y los representantes holandeses acordaron unánimemente que el Reichskommissar se había comportado de forma digna ${ }^{119}$.

Con el mismo optimismo, el 2 de mayo Seyss-Inquart escribió al sucesor de Hitler como Führer y presidente del Reich, el gran almirante Karl Dönitz, hablándole de la reunión para pedir instrucciones personales o poderes ejecutorios. "Por la seriedad de la oferta y la actitud adoptada hacia mí, me dio la impresión de que también es posible

\footnotetext{
${ }^{116}$ NIOD, 216h, inv.no. 93, Mensaje Seyss-Inquart al Cuartel de aliados, 26 de abril 1945; Ibid., 'Report on food droppings'; Dando-Collins, Operation Chowhound, p. 119. Para saber más de la misión, véase: Hans Onderwater, Operatie 'Manna': De Geallieerde Voedseldroppings April/Mei1945 (Weesp, 1985), pp. 30-33.

${ }^{117}$ NARA, 331, 2/118, Mensaje Eisenhower a los Jefes de Estado Mayor, 1 de mayo 1945; NIOD, 212a, inv.no. 162, Diario Hirschfeld, 1 de mayo 1945. Véase también: TNA, PREM 3/221/12; Eisenhower, Eisenhower's own Story of the War, p. 115.

118 NARA, 331, 2/118, Memorando para Eisenhower de Bedell Smith, 1 de mayo 1945; Francis de Guingand, Operation Victory (Londres, 1947), pp. 450-451.

${ }^{119}$ NIOD, 212a, inv.no. 162, Diario Hirschfeld, 1 de mayo 1945.
} 
tener negociaciones serias sobre otras cuestiones generales de interés para el Reich" ${ }^{120}$. No obstante, ese mismo día Blaskowitz había escrito al OKW, afirmando que Eisenhower había pedido una mayor cantidad de entregas por aire y que él lo había rechazado por razones de objetivos militares. "Mi tarea en la batalla no ha cambiado"121.

Durante 10 días consecutivos, bombarderos pesados Lancaster de la RAF y B-17 de la USAAF arrojaron comida en el oeste de los Países Bajos. Los envíos por aire cubrieron un periodo de tiempo en el que los Países Bajos se enfrentaban a una transición compleja de la guerra a la paz. Tras la reunión del 30 de abril, Dönitz convocó a Seyss-Inquart en Flensburg, poco después el primero fue arrestado por las fuerzas aliadas que ocupaban Hamburgo. El 4 de mayo, Montgomery aceptó la rendición incondicional de todas las fuerzas armadas alemanas en el noroeste de Europa. Al siguiente día, el teniente general Charles Foulkes del 1er Cuerpo Canadiense convocó al General Blaskowitz en el Hotel de Wereld, en la ciudad de Wageningen, para firmar otro documento de rendición. Tras estudiarlo durante 24 horas, Blaskowitz volvió y firmó todas las condiciones. Las fuerzas alemanas en los Países Bajos se habían rendido oficialmente, y por fin llegó la ayuda a raudales.

Tras la derrota de la Alemania nazi, las personas de contacto más importantes en la administración holandesa del abastecimiento, Schwebel y Von der Wense, fueron internados en campos de prisioneros de guerra aliados durante varios años $\mathrm{y}$, junto con Hirschfeld, tuvieron que testificar en Núremberg contra su antiguo Reichskommissar. E1 hecho de que Von der Wense y Louwes permanecieran en contacto durante los primeros años tras la guerra refuerza la idea de que su cooperación había sido en efecto cordial, dentro de los límites de la guerra y la ocupación ${ }^{122}$. Para Seyss-Inquart, la hambruna jugó un papel importante en su juicio en Núremberg. La acusación oficial declaraba en gran detalle que como Reichskommissar, Seyss-Inquart era responsable de la hambruna en los Países Bajos y de la gran mortandad que la siguió (inicialmente estimada en 50.000 muertes, después modificada a 25.000). Muchas de esas muertes, alegaron

\footnotetext{
${ }^{120}$ BA, R3/1625, Carta de Seyss-Inquart a Dönitz, 2 de mayo 1945.

${ }^{121}$ Ibid., Carta Blaskowitz a OKW, 2 de mayo 1945.

${ }^{122}$ Ibid., inv.no. 110, Correspondencia entre Louwes y la familia Von der Wense, 1946-1947.
} 
(incorrectamente), eran presuntamente niños ${ }^{123}$. Cuando se le preguntó sobre qué había hecho para mejorar las condiciones, Seyss-Inquart respondió:

Le di al Secretario Hirschfeld toda la autoridad, incluida la del transporte, y este hombre, aunque con vacilación y de mala gana, restableció el tráfico - y él puede confirmar que yo le apoyé en todo lo posible. Los suministros de comida llegaron a Holanda. Pero habían pasado muchas semanas en vano. Luego, en mi sector de influencia, proporcioné más asignaciones, de las que puede testificar Von der Wense y creo que el testigo Schwebel le puede dar información en su interrogatorio $^{124}$.

Seyss-Inquart también afirmó que "la cuestión de la alimentación en Países Bajos fue sin duda la cuestión más difícil de toda la administración y, creo, debido a las particularidades del caso, fue la más difícil de todos los territorios ocupados." 125 Tras escuchar a Hirschfeld, Von der Wense y Schwebel, entre otros, los jueces de Núremberg retiraron los cargos contra Seyss-Inquart por su alegada responsabilidad en la hambruna del oeste de los Países Bajos. Seyss-Inquart pidió a la reina holandesa Wilhelmina el indulto real debido a sus "esfuerzos para proteger a los holandeses del desastre en el periodo de diciembre de 1944 a abril de 1945", pero no obtuvo respuesta. Por todas las otras atrocidades que cometió durante la ocupación de los Países Bajos, inclusive su responsabilidad en la muerte de tres cuartos de los 140.000 civiles judíos, el 16 de octubre de 1946 Seyss-Inquart fue ahorcado ${ }^{126}$.

\section{CONCLUSIÓN}

Aunque muchos estudios siguen afirmando que el Invierno del Hambre fue el producto de la explotación del imperio nazi y de las políticas del hambre, un estudio más detallado revela que el papel del ocupante alemán en la causa y mantenimiento de las condiciones de hambruna en el oeste de los Países Bajos es mucho más compleja. Obviamente, sin la ocupación alemana no habría habido hambruna en los Países Bajos. Pero dentro del contexto de la guerra y la ocupación, la hambruna fue causada y

\footnotetext{
${ }^{123}$ Ibid., Juicio Núremberg Seyss-Inquart, 11 de junio 1946, p. 11430.

${ }^{124}$ Ibid., p. 11432

${ }^{125}$ Ibid., p. 11428.

${ }^{126}$ Koll, Arthur Seyss-Inquart, pp. 611-613.
} 
exacerbada por una conjunción de problemas de transporte y distribución - tanto intencionales como no. Este artículo ha mostrado que es imposible identificar una única causa entre los factores, como hicieron estudios anteriores, ya que todas las variables están interconectadas. De hecho, al inicio de la cadena de acontecimientos, las autoridades civiles alemanas desplegaron activamente la amenaza del hambre, pero la hambruna real en los Países Bajos demostró ser más una amenaza a su propia posición política y militar que un arma útil de guerra. Cuando las autoridades civiles alemanas levantaron el embargo de transporte a principios de noviembre de 1944 para evitar disturbios entre la población y la enfermedad, estas circunstancias no habían producido la hambruna en toda su expresión.

El cambio alemán a finales de 1944 de pasar de retener alimentos a cooperar para "evitar lo peor", diferencia mucho el caso holandés de otros casos de alimentación en la Europa ocupada por los nazis, sobre todo los de Europa del Este y Grecia. En vez de desplegar el hambre para acabar con la resistencia holandesa, las autoridades civiles alemanas permitieron que las instituciones de ayuda surgieran y ayudaran a los responsables del abastecimiento para recuperar el control del sistema alimentario. En este contexto, este estudio demuestra que es imposible referirnos al ocupante alemán como una entidad política o legislativa coherente. Al igual que en la situación antes de la crisis, las autoridades alemanas en los Países Bajos estaban divididas internamente ya que la acciones de la Wehrmacht y la Kriegsmarine a menudo desafiaban las políticas marcadas por la administración civil alemana. Además de los motivos militares y políticos para aliviar la crisis, también es posible que los oficiales alemanes decidieran utilizar la oportunidad que presentaba la hambruna para mostrar un liderazgo bueno y benevolente, permitiendo y apoyando los esfuerzos de ayuda humanitaria. La actitud alemana se ve reflejada en el intento de Seyss-Inquart, mientras estaba presente en el juicio de Núremberg, de obtener el indulto real basado en sus esfuerzos "para salvar a los holandeses del hambre".

Futuras investigaciones podrían desarrollar un estudio comparativo de las respuestas alemanas a las condiciones de hambruna en los territorios ocupados, para arrojar más luz sobre la estratificación y diversidad de las políticas del hambre alemanas en toda Europa. Al hacerlo, será importante hacer una distinción clara entre las consecuencias intencionales y no intencionales de la toma de decisiones, reconociendo 
por tanto la heterogeneidad entre y dentro de los regímenes de ocupación alemanes, lo que ha sido esencial para entender la hambruna holandesa. Además, un estudio comparativo que incluya las políticas de alimentación y hambre de los aliados y las administraciones nacionales ayudaría también a entender mejor la dimensión completa de por qué el hambre y la hambruna eran claves en las estrategias políticas y militares durante la Segunda Guerra Mundial, mirando más allá de las visiones que se centran en la Alemania nazi.

\section{BIBLIOGRAFÍA}

Aykroyd, Wallace R. The Conquest of Famine (London, 1974).

Beaumont, Joan. 'Starving for Democracy: Britain's Blockade of and Relief for Occupied Europe, 1939-1945', War \& Society 8 (1990): pp. 57-82.

Beevor, Antony. Arnhem: The Battle for the Bridges, 1944 (London, 2018).

Berkhoff, Karel C. Harvest of Despair: Life and Death in Ukraine under Nazi Rule (Cambridge Mass., 2004)

Blom, J.C.H. "Nazificatie en Exploitatie," in De Organisatie van de Bezetting, eds. Henk Flap and Wil Arts (Amsterdam, 1997).

Burger, George C.E. et al. eds., Malnutrition and Starvation in Western Netherlands: September 1944-July 1945, part I (The Hague, 1948)

Buruma, Ian. Year Zero: A History of 1945 (New York, 2013).

Collingham, Lizzie. The Taste of War: World War Two and the Battle for Food (London, 2011).

Dando-Collins, Stephen. Operation Chowhound: The Most Risky, Most Glorious US Bomber Mission of WWII (New York, 2015).

De Guingand, Francis. Operation Victory (London, 1947)

De Jong, Loe. Het Koninkrijk der Nederlanden in de Tweede Wereldoorlog 4 (The Hague, 1972)

De Rooy, Piet. Republiek van Rivaliteiten: Nederland sinds 1813 (Amsterdam, 2002)

De Waal, Alex. Mass Starvation: The History and Future of Famine (Cambridge, 2018).

De Zwarte, Ingrid. 'Coordinating Hunger: The Evacuation of Children during the Dutch Food Crisis, 1945', War \& Society 35 (2016): 132-149.

--. 'Fighting Vulnerability: Child Feeding Initiatives during the Dutch Hunger Winter', in Societies under Occupation in World War II, pp. 293-310.

Devereux, Stephen. Theories of Famine (New York, 1993). 
Dols, M. J. L. and Van Arcken, D.J.A.M., "Food Supply and Nutrition in the Netherlands during and immediately after World War II," The Milbank Memorial Fund Quarterly 24 (1946)

Eisenhower, Dwight D. Eisenhower's Own Story of the War: The Complete Report by the Supreme Commander General Dwight D. Eisenhower on the War in Europe form the Day of Invasion to the Day of Victory (New York, 1946).

Fennema, Meindert and Rhijnsburger, John. Dr. Hans Max Hirschfeld: Man van het Grote Geld (Amsterdam, 2007)-

Fest, Joachim. Speer: Eine Biographie (Berlin, 1999)

Foray, Jennifer L. "The 'Clean Wehrmacht' in the German-Occupied Netherlands, 1940-5," Journal of Contemporary History 45 (2010).

Futselaar, Ralf D. Lard, Lice and Longevity: A Comparative Study on the Standard of Living in Occupied Denmark and the Netherlands, 1940-1945 (Amsterdam, 2008)

Gerhard, Gesine. "Food and Genocide: Nazi Agrarian Politics in the Occupied Territories of the Soviet Union," Contemporary European History 18 (2009): 45-65.

Gerhard, Gesine. Nazi Hunger Politics: A History of Food in the Third Reich (Lanham, 2015).

Gerlach, Christian. Krieg, Ernährung, Völkermord: Deutsche Vernichtuinspolitiek im Zweiten Weltkrieg (Zürich, 2001).

Gulmans, J.J. 'Operatie Market Garden', in De Bevrijding van Nederland, 1944-1945: Oorlog op de Flank, eds. Christ Klep and Ben Schoenmaker (The Hague, 1995).

Herbert, Ulrich. Best: Biographische Studien über Radikalismus, Weltanschauung und Vernunft 1903-1989, (5 ${ }^{\text {th }}$ ed., Bonn, 2011).

Hionidou, Violetta. Famine and Death in Occupied Greece, 1941-1944 (Cambridge, 2006).

Hirschfeld, Gerhard. 'Chronology of Destruction', in Policies of Genocide: Jews and Soviet Prisoners of War in Nazi Germany, ed. Idem (Boston, 1986), pp. 145-56.

--. Bezetting en Collaboratie: Nederland tijdens de Oorlogsjaren 1940-1945 in Historisch Perspectief (Haarlem, 1991)

Hirschfeld, Hans M. Herinneringen uit de Bezettingstijd (Amsterdam, 1960)

Klemann, Hein A.M. Nederland 1938-1948: Economie en Samenleving in Jaren van Oorlog en Bezetting (Amsterdam, 2002)

Koll, Johannes, Arthur Seyss-Inquart und die deutsche Besatzungspolitiek in den Niederlanden 1940-1945 (Vienna, 2015).

Klemann, Hein A. M. and Kudryashov, Sergei. Occupied Economies: An Economic History of Nazi-Occupied Europe, 1939-1945 (London, 2012).

Lindberg, John. Food, Famine and Relief 1940-1946 (Genève, 1946).

Louwes, Stephanus L. "De Voedselvoorziening," in Onderdrukking en Verzet II, ed. Johannes J. van Bolhuis (Arnhem, 1950) 
Lowe, Kevin. Savage Continent: Europe in the Aftermath of World War II (London, 2012)

Maas, Walter B. The Netherlands at War: 1940-1945 (London, 1970)

Mazower, Mark. Hitler's Empire: How the Nazis Ruled Europe (New York, 2008)

Moore, Bob. "The Netherlands, 1940-45," in The Civilian in War: Occupation and the Home Front in World War II, ed. Jeremy Noakes (Exeter, 1992)

--. "The Western Allies and Food Relief to the Occupied Netherlands, 1944-1945", War \& Society 10 (1992)

Nissen, Mogens R. 'Danish Food Production in the German War Economy', in Food and Conflict in Europe in the Age of the Two World Wars, ed. Frank Trentmann and Flemming Just (Basingstoke, 2006)

Onderwater, Hans. Operatie 'Manna': De Geallieerde Voedseldroppings April/Mei1945 (Weesp, 1985)

Romijn, Peter. Burgemeesters in Oorlogstijd: Besturen tijdens de Duitse Bezetting (Amsterdam, 2006).

Rüter, A.J.C. Rijden en Staken. De Nederlandse Spoorwegen in Oorlogstijd (The Hague, 1960)

Sereny, Gitta. Albert Speer: His Battle with the Truth (London and Basingstoke, 1995)

Shephard, Ben. 'Becoming Planning Minded: The Theory and Practice of Relief 19401945', Journal of Contemporary History 43 (2008): pp. 405-19.

Sijes, Ben A. De Razzia van Rotterdam: 10-11 November 1944 (The Hague, 1951).

--. De Arbeidsinzet: De Gedwongen Arbeid van Nederlanders in Duitsland (2nd ed., The Hague, 1990)

Snyder, Timothy. Bloodlands: Europe Between Hitler and Stalin (London, 2011), pp. 162-182.

Stein, Zena; Susser, Mervyn and Saenger, Gerhard. Famine and Human Development: The Dutch Hunger Winter of 1944-1945 (New York, 1975).

Tönsmeyer, Tatjana. "Supply Situations: National Socialist Policies of Exploitation and Economies of Shortage in Occupied Societies during World War II," in Coping with Hunger and Shortage under German Occupation in World War II, eds. Tönsmeyer, Peter Haslinger and Agnes Laba (London, 2018), pp. 3-23.

Tooze, Adam. The Wages of Destruction: The Making and Breaking of the Nazi Economy (London: Allen Lane, 2006).

Trienekens, Gerard M.T. "The Food Supply in The Netherlands during the Second World War," in Food, Science, Policy and Regulation in the Twentieth Century: International and Comparative Perspectives, eds. David F. Smith and Jim Phillips (London, 2000), pp. 117-134

--. Tussen ons Volk en de Honger: De Voedselvoorziening 1940-1945 (Utrecht, 1985)

Van Rossem, P.V.J.. Het ontstaan van het Inter Kerkelijk Bureau en zijn organisatie (Amsterdam, 1984) 
Voglis, Polymeris. "Surviving Hunger: Life in the Cities and the Countryside during the Occupation", in Surviving Hitler and Mussolini: Daily Life in Occupied Europe, eds. Robert Gildea, Olivier Wieviorka and Anette Warring (Oxford, 2006), 1641.

Warmbrunn, Werner. The Dutch under German Occupation, 1940-1945 (Stanford, 1963),

Wassenaar, Aart W. Van Winterhulp via Oost-Compagnie en Marseille naar Rode Kruis: De Loopbaan van Carel Piek Voor, Tijdens, en Na de Bezettingstijd 1940-1945. Een Geschiedenis van Idealisme en Collaboratie (Soesterberg, 2016)

Winstone, Martin. The Dark Heart of Hitler's Europe: Nazi Rule in Poland under the General Government (New York, 2015).

Zweig, Ronald W. 'Feeding the Camps: Allied Blockade Policy and the Relief of Concentration Camps in Germany, 1944-45', The Historical Journal 41 (1998): pp. 825-51 